\title{
A MULTI-GENE SYNAPTIC PLASTICITY ARRAY IDENTIFIES CANDIDATE MOLECULAR UNDERPINNINGS OF COGNITIVE AND MOOD DEFICITS IN RATS WITH HEART FAILURE
}

Marise B. Parent*, Hildebrando Candido Ferreira-Neto*, Ana Rafaela Kruemmel*, Ferdinand Althammer, Atit A. Patel, Sreinick Keo, Kathryn E.Whitley, Daniel N. Cox, and Javier E. Stern ${ }^{\#}$ Neuroscience Institute, Georgia State University, Atlanta GA USA *co-first author

Running title: HF-induced changes in mood, cognition and brain gene expression

Keywords: amygdala, hippocampus, paraventricular nucleus, synaptic plasticity, behaviour Table of Content Category: Cardiovascular

\section{Corresponding author}

Javier E. Stern M.D. Ph.D.

Neuroscience Institute

Georgia State University

145 Piedmont Ave SE

Atlanta, GA 30303

Phone: (404)-413-6678

E-mail: jstern@gsu.edu 


\begin{abstract}
Chronic heart failure (HF) is a serious disorder that afflicts more than 26 million patients worldwide. HF is comorbid with depression, anxiety and memory deficits that have serious implications for quality of life and self-care in patients who have HF. Despite evidence that cognitive performance is worse in HF patients with reduced ejection fraction than in HF patients with preserved cardiac function, there are few studies that have assessed the effects of severely reduced ejection fraction $(\leq 40 \%)$ on cognition in non-human animal models. Moreover, very limited information is available regarding the effects of HF on genetic markers of synaptic plasticity in brain areas critical for memory and mood regulation. We induced HF in male rats and tested mood and anxiety (sucrose preference and elevated plus maze) and memory (spontaneous alternation and inhibitory avoidance) and measured the simultaneous expression of 84 synaptic plasticity-associated genes in dorsal (DH) and ventral hippocampus (VH), basolateral (BLA) and central amygdala (CeA,) and prefrontal cortex (PFC). We also included the hypothalamic paraventricular nucleus (PVN), which has been implicated in neurohumoral activation in HF. Our results show that rats with severely reduced ejection fraction displayed signs of polydipsia, anhedonia, increased anxiety, and impaired memory in both tasks. HF also produced a drastic downregulation of synaptic-plasticity genes in PFC and PVN, moderate decreases in DH and CeA and minimal effects in BLA and VH. Collectively, these findings identify candidate brain areas and molecular mechanisms underlying HF-induced disturbances in mood and memory.
\end{abstract}




\section{INTRODUCTION}

Chronic heart failure (HF) is a serious cardiovascular disorder that afflicts more than 26 million patients worldwide (Ambrosy et al., 2014). In the United States, it is estimated that 6.2 million people suffer from HF and the prevalence is projected to increase by $46 \%$ by 2030 , more than doubling the cost of health care from $\$ 30.7$ to $\$ 68.8$ billion (Benjamin et al., 2019). Once established, HF morbidity, prognosis and mortality are largely influenced by the degree of neurohumoral activation, which is a pathophysiological mechanism that involves increased centrally-driven sympathetic activity and elevated circulating levels of neurohormones, including vasopressin, angiotensin II and endothelins among others (Packer, 1988; Mancia, 1990; Zucker et al., 2004). A major focus of research in the last decade has been to uncover the precise mechanisms underlying neurohumoral activation using experimental animal models of HF. Collectively, this research demonstrates that the hypothalamic paraventricular nucleus (PVN) is a major neuronal substrate contributing to neurohumoral activation in HF (Cohn et al., 1981; Goldsmith et al., 1983; Cohn et al., 1984; Hodsman et al., 1988), and that neuroinflammation (Kang et al., 2008; Kang et al., 2009; Kang et al., 2010; Rana et al., 2010; Yu et al., 2018) and altered excitatory and inhibitory synaptic balance (Patel, 2000; Zhang et al., 2002; Kleiber et al., 2008; Han et al., 2010; Zheng et al., 2011) are likely underlying cellular mechanisms.

It is now becoming well-accepted that, in addition to neurohumoral activation and the associated systemic cardiac, renal and vascular complications, HF is comorbid with depression, anxiety and memory deficits, both in human patients (Rutledge et al., 2006; Angermann et al., 2012; Lossnitzer et al., 2013; Cameron et al., 2014; Cannon et al., 2017) and experimental animal models (Toledo et al., 2019; Wang et al., 2019). These mood and cognitive disturbances have serious implications for quality of life and self-care in patients who have HF because hospital readmission and mortality rates are significantly higher in HF patients that have depression and/or cognitive impairments compared to HF patients without these comorbidities (Dickson et al., 2007; Pressler et al., 2010a; Lee et al., 2013; Lossnitzer et al., 2013). Thus, it is critical to identify the precise neurobiological mechanisms and substrates that underlie these mood and cognitive disturbances during HF in order to identify treatments that may improve quality of life and decrease mortality in this prevalent disease.

The hippocampus, amygdala, and prefrontal cortex (PFC) play critical roles in learning, memory and mood states. Hippocampal pathology severely impairs memory (Squire \& Cave, 
1991; Bird, 2017; Ekstrom \& Ranganath, 2018) and produces depression and anxiety in humans (Sahay \& Hen, 2007; Cole et al., 2011; Kheirbek et al., 2012) and non-human animals (Bannerman et al., 2004; Shapiro et al., 2006). Similarly, damage to the amygdala in humans and animals disrupts anxiety and impairs emotional memory (Lehmann et al., 2003; Etkin \& Wager, 2007; Davis et al., 2010; Bocchio et al., 2017). Likewise, damage to the PFC produces anhedonia, anxiety and memory impairments in non-human models (Shah \& Treit, 2003; Banasr \& Duman, 2008; de Visser et al., 2011; Kabir et al., 2017; Woloszynowska-Fraser et al., 2017) and mood disorders in humans (Liu et al., 2017; Belleau et al., 2019; Ong et al., 2019). In HF patients, neurocognitive impairments, including learning and working memory deficits, delayed recall, depression, and anxiety are correlated with significant cerebral grey matter loss and damage in brain areas relevant to cognitive function, including hippocampus, amygdala and PFC (Woo et al., 2003; Almeida et al., 2012; O'Donnell et al., 2012; Woo et al., 2015; Roy et al., 2017). However, the precise mechanisms through which HF produces mood and cognitive impairments are not known. This question is difficult to address in human patients due to the influence of genetic, environmental and psychosocial variables that cannot be controlled. As a result, it is critical to develop valid animal models of mood and cognitive disturbances in HF in order to begin to identify underlying mechanisms.

Despite evidence that cognitive performance is worse in HF patients with reduced ejection fraction than in HF patients with preserved cardiac function (Jefferson et al., 2011; Leto \& Feola, 2014), there are limited studies that have assessed the effects of severely-reduced ejection fraction $(\leq 40 \%)$ on cognition in non-human animal models. Moreover, very limited information is available regarding the effects of HF on genetic and molecular markers of synaptic plasticity in brain areas critical for specific types of memory (e.g., spatial and emotional memory) and mood regulation. This information is necessary to begin to understand the mechanisms through which HF impairs mood and memory. As a result, in the present study we aimed to investigate the effects of HF that is characterized by severe reductions in ejection fraction on behavioral measures of mood and memory that are known to be dependent on the hippocampus, amygdala and PFC. To this end, we induced HF using a well-established ischemic HF rat model (Biancardi et al., 2011; Potapenko et al., 2013; Ferreira-Neto et al., 2017; Ferreira-Neto \& Stern, 2019) and then tested the rats in a battery of behavioral tests that are minimally stressful to assess anhedonia and anxiety (sucrose preference test [SPT] and elevated plus maze [EPM], respectively) as well as spatial 
working memory (spontaneous alternation; SA) and emotional long-term memory (one-trial inhibitory avoidance; IA). Moreover, we used an unbiased quantitative real time polymerase reaction (qRT-PCR) approach to identify the effects of HF on the simultaneous expression of 84 genes critical for synaptic plasticity in brain areas critical for mood and memory, including dorsal and ventral hippocampus (DH and $\mathrm{VH}$, respectively), basolateral and central amygdala (BLA and CeA, respectively), PFC and PVN.

\section{MATERIALS AND METHODS}

\section{Subjects}

Male Wistar rats (5 wks-old, 180-200 g) were purchased from Envigo Laboratories (Indianapolis, IN) and housed in Optirat cages (Animal Care Systems, Centennial, CO, USA) on a $12 \mathrm{~h}$ light-dark cycle (lights on at 8:00 am) with ad libitum access to pelleted food and water in their home cages unless otherwise stated. Rats were housed individually following surgery and during behavioral testing. All procedures were performed in compliance with the NIH guidelines for the care of laboratory animals and approved by the Georgia State University Institutional Animal Care and Use Committee.

\section{Induction of heart failure (HF)}

HF was induced by coronary artery ligation as described previously (Biancardi et al., 2011; Ferreira-Neto et al., 2017; Ferreira-Neto \& Stern, 2019). Briefly, animals were anesthetized with isoflurane (2-4\%) and intubated for mechanical ventilation. A left thoracotomy was performed and the heart exteriorized. The ligation was placed on the main diagonal branch of the left anterior descending coronary artery. Buprenorphine SR-LAB $(0.5 \mathrm{mg} / \mathrm{kg} \mathrm{sc}$; Zoo Pharm, Windsor, CO, USA) was given immediately after surgery to minimize postsurgical pain. Sham control animals underwent the same procedure with the exception that the coronary artery was not occluded. Transthoracic echocardiography (Vevo 3100 systems, Visual Sonics, Toronto, ON, Canada) was performed 4 weeks after surgery under light isoflurane (3-4\%) anesthesia. The measurements of the left ventricle internal diameter and its posterior and anterior walls in systole and diastole, and the ejection fraction and fractional shortening were obtained throughout the cardiac cycle from the short-axis motion imaging mode. 


\section{Behavioral measures of $\operatorname{mood}$ and memory}

Behavioral testing was conducted 5-10 weeks after the induction of HF starting with the measures of mood in one cohort and memory in another. All tests were selected because they assessed mood and cognition in a minimally stressful manner and all behavioral testing and scoring were conducted by an experimenter blind to HF condition. SPT is a commonly used measure of anhedonia, which is a major symptom of depression (Willner et al., 1987). SPT relies on the natural preference of rodents for sweet foods and solutions; a decreased preference for a sweet solution versus tap water is assumed to reflect depression-like behavior (Krishnan \& Nestler, 2011; Liu et al., 2018). Manipulations that impair DH or PFC function attenuate sucrose preference (Banasr \& Duman, 2008; Liu et al., 2015; Kabir et al., 2017), which is consistent with evidence indicating that damage to these areas produces depression in humans (Almeida et al., 2012; O'Donnell et al., 2012). SPT was assessed in home cages with continuous ad libitum access to standard chow. Rats (Sham $\mathrm{n}=12$; HF $\mathrm{n}=8)$ were first habituated to sucrose $(1 \% \mathrm{wt} / \mathrm{vol})$ by removing their water and giving them access to two bottles that both contained $1 \%$ sucrose for $24 \mathrm{~h}$. The next day they were adapted to the preference test by giving them access to one bottle containing $1 \%$ sucrose and one containing tap water for $18 \mathrm{~h}(2 \mathrm{pm}$ to $8 \mathrm{am})$. For the preference test the following day, all fluids were removed for $12 \mathrm{~h}(8 \mathrm{am}$ to $8 \mathrm{pm})$ and the rats were then given access to one bottle of tap water and one bottle of $1 \%$ sucrose for $12 \mathrm{~h}$. To avoid biases in drinking behavior based on the location of the bottle (i.e., left versus right), the position of the sucrose and water bottles were counterbalanced each day (Strekalova et al., 2004). Sucrose preference was calculated by dividing the amount of sucrose ingested by the total amount of fluid consumed on the sucrose preference testing day. The data from four rats ( $\operatorname{Sham~} n=3 ; \mathrm{HF} n=1$ ) were excluded due to excessive leaking from bottles. At the end of the sucrose preference test the rats were weighed, and chow consumption and water intake were measured for $24 \mathrm{~h}$.

The rats were then tested in the elevated plus maze (EPM) approximately 10 days later. They were handled for $3 \mathrm{~min} /$ day for 2 days before the EPM test and all testing was conducted during the light phase between 8:00 am and 12:00 pm. The EPM is a well-established behavioral test of anxiety (Pellow et al., 1985; Kraeuter et al., 2019) that relies on the natural tendency of rodents to prefer dark enclosed spaces and fear height and open spaces, and their innate motivation to explore novel environments (Montgomery, 1955; Handley \& Mithani, 1984). EPM is dependent on the integrity of CeA (Ventura-Silva et al., 2013), BLA (Yin et al., 2019) and PFC (Lisboa et 
al., 2010; de Visser et al., 2011), which is congruent with a wealth of evidence indicating that these brain areas are involved in regulation of mood (Gallagher \& Chiba, 1996; Price \& Drevets, 2010; Teffer \& Semendeferi, 2012; Prager et al., 2016; Dixon et al., 2017). The plus-shaped stainless-steel apparatus was elevated $50 \mathrm{~cm}$ above the floor and composed of four arms $(50 \mathrm{~cm} \mathrm{x}$ $12 \mathrm{~cm}$ ). Two arms were surrounded by a $40 \mathrm{~cm}$ high black acrylic wall (i.e., closed arms) and two arms did not have walls (i.e., open arms). The rats were placed in the central square $(12 \times 12 \mathrm{~cm})$ facing the closed arm, their behavior was video-recorded for $5 \mathrm{~min}$, and the video-recordings were analyzed by a trained observer. The apparatus was cleaned with $70 \%$ ethanol after each rat was tested. An arm entry was defined as entering an arm with all four paws. Measures of anxiety included the percentage of time spent in the open arms [(time spent in open arm/total time spent on the maze $) \times 100]$ and the percentage of entries into the open arms [(open arm entries/ total arm entries) x 100]. Risk assessment was also used as a measure of anxiety (Holly et al., 2016). Specifically, anxious animals make more stretch attend attempts, which were operationally defined as when a rat stretched its body towards an open arm after having been motionless, and then retracted (Mikics et al., 2005; Holly et al., 2016).

Rats (Sham $n=17$; HF $n=13$ ) were handled for $3 \mathrm{~min} /$ day for 2 days before SA and IA training, all testing was conducted during the light phase between 8:00 am and 12:00 pm, and the apparatuses were cleaned with $70 \%$ ethanol after each rat was tested. Rats were first assessed in SA, which is a test of spatial working memory (Richman, 1986; Lalonde, 2002). The underlying assumption is that rats must remember their visits to previous locations in order to successfully alternate between spatial locations. This is supported by the finding that removing extra-maze cues or increasing the interval between arm choices decreases alternation scores (Richman, 1986; Lalonde, 2002). SA is a task that depends on the integrity of the DH (Dillon et al., 2008; Sakaguchi \& Sakurai, 2020) and PFC (Delatour \& Gisquet-Verrier, 1996; Woloszynowska-Fraser et al., 2017). To assess SA, eat rat was placed in a Y-maze composed of three equally spaced arms $\left(60^{\circ}\right.$; $60 \mathrm{~cm} \times 17.5 \mathrm{~cm})$. The floor of each arm was composed of stainless steel $(3.5 \mathrm{~cm}$ wide) and the top (14 cm wide) was covered with black Plexiglas. All of the rats were placed in the same starting arm of the Y-maze and allowed to explore the maze freely for $8 \mathrm{~min}$. An alternation was defined as entering three different arms consecutively, and a percent alternation score was computed by dividing the number of alternations made by the number of arms entered minus two and then 
multiplying the resulting quotient by 100 . The number of arms entered was used as a measure of activity.

The rats were then given training in the one-trial IA task approximately 15 days after SA testing. IA is commonly used to measure emotional, long-term memory (Jarvik \& Kopp, 1967; Vazdarjanova, 2002) and is dependent on intact functioning of DH (Quevedo et al., 1997; Izquierdo et al., 2000; Quiroz et al., 2003), VH (Giovannini et al., 2005), BLA (Parent et al., 1992; Nobre, 2013), CeA (Roozendaal \& McGaugh, 1997), and PFC (Giovannini et al., 2005; Torkaman-Boutorabi et al., 2015; Torres-Garcia et al., 2017). Each rat was placed into a troughshaped apparatus $(91 \times 15 \times 20 \times 6.4 \mathrm{~cm})$ that was separated into two compartments by a retractable guillotine door. The dark compartment (60 cm long) had a metal floor through which shock could be delivered. A 15-W light was placed over the lighted compartment $(31 \mathrm{~cm} \mathrm{long})$ and was the only source of illumination in the room. For training, each rat was placed into the lighted compartment facing away from the retractable door and the door was then opened after the rat turned toward the door or after $12 \mathrm{~s}$ had passed. When the rat entered the dark compartment with all four paws, it was given a footshock $(1.2 \mathrm{~mA}, 2 \mathrm{~s})$ and then removed from the apparatus and returned to its home cage. The current level was assessed regularly throughout the course of the experiment with a digital multi-meter (AstroAI AM33D). For the retention test $24 \mathrm{~h}$ later, each rat was placed in the lighted compartment, the retractable door was lowered, and the latency (s) to cross over to the dark compartment (maximum $600 \mathrm{~s}$ ) was recorded and used as a measure of retention. Footshock was not delivered on the retention test.

\section{Unbiased qRT-PCR array approach to assess the impact of HF on 84 molecular markers of synaptic plasticity}

Approximately 10 weeks after surgery, rats (Sham $\mathrm{n}=5$; HF $\mathrm{n}=5$ ) were anesthetized deeply with pentobarbital (Euthasol, Virbac, ANADA \#200-071, Fort Worth, TX, USA, 390 $\mathrm{mg} / \mathrm{kg}$, i.p.), decapitated quickly with a guillotine, and their brains dissected, frozen in 2methylbutane (Fisher Scientific, USA) at $-40^{\circ} \mathrm{C}$ and then stored at $-80^{\circ} \mathrm{C}$. To collect micropunches, brains were allowed to reach $-20^{\circ} \mathrm{C}$ and then mounted in a cryostat (CM3050S; Leica Microsystems, Wetzlar, Germany) and brain slices $(300 \mu \mathrm{m})$ were obtained (infralimbic and prelimbic PFC, 3.7 to $2.2 \mathrm{~mm}$; PVN, -1.4 to $-2.12 \mathrm{~mm}$; BLA and CeA, -1.8 to $-3.14 \mathrm{~mm}$; $\mathrm{DH}$, -2.8 to $-4.16 \mathrm{~mm}$ and $\mathrm{VH},-4.8$ to $-6.04 \mathrm{~mm}$ from bregma) (Paxinos \& Watson, 2006). A $2.0 \mathrm{~mm}$ 
stainless-steel punch was used to collect four central punches/rat from PFC, PVN, and DH and 10 bilateral punches/rat from VH. A $1.0 \mathrm{~mm}$ punch was used to collect eight bilateral punches from BLA and CeA. The micropunched tissues were kept on dry ice until RNA extraction. RNA extraction and isolation were performed using the miRNAeasy Mini kit (Qiagen, Hilden, Germany) and the QIAzol Lysis Reagent (Qiagen) following manufacturers' protocols. RNA concentration was measured using NanoDrop One (Thermo Scientific, Waltham, Massachusetts, USA) and was in the range of $115-220 \mathrm{ng} / \mu \mathrm{L}$ prior to cDNA synthesis. cDNA synthesis was performed using the RT2 First Strand Kit (Cat. No. 330401, Qiagen) and the SimpliAmp Thermal Cycler (Applied Biosystems, Thermo Fisher Scientific) following the manufacturers' protocols. The gene array reaction was performed using the $\mathrm{RT}^{2}$ Profiler ${ }^{\mathrm{TM}}$ Rat Synaptic Plasticity PCR Array (Cat. No. 330231, Qiagen) following the manufacturer's protocol, and all reactions were performed in triplicate for each brain region and treatment condition using a Roche Lightcycler 96 (Roche Life Science, Indianapolis, IN, USA). This kit measures the expression of 84 genes critical for synaptic alterations implicated in memory and mood, including immediate early genes (IEG)s, genes implicated in long-term potentiation (LTP) and long-term depression (LTD), cell adhesion and extracellular matrix molecules, CREB cofactors, and neuronal receptors (plus five housekeeping genes and two negative controls).

\section{Validation of gene array results}

To validate the array findings, qRT-PCR was conducted using specific 10x QuantiTect primers diluted in $1.1 \mathrm{~mL}$ TE $\mathrm{pH} 8.0$ (Qiagen). The genes that were analyzed were Adcyl (QT00386421), Arc (QT00373086), Homer1 (QT00391111), Mapk1 (QT00190379), and Nr4a1 (QT00181048). B2m (QT00176295) was used as the reference gene. All individual qRT-PCR reactions (brain region, primer and condition) were performed in triplicate.

\section{Statistical analyses}

Statistical analyses were performed using IBM SPSS Statistics 25 (IBM, Armonk, New York) and GraphPad Prism 7 (GraphPad Software, San Diego, CA). Data points that were two standard deviations from the mean were considered outliers and excluded from further analyses. Given that we predicted that HF would impair mood and memory and increase thirst (Allida et al., 2015), unpaired one-tailed $t$-tests were used to assess differences between Sham and HF rats in the 
behavioral tests and measures of water intake. Two-tailed tests were used to compare chow intake and body mass. Behavioral and body mass data are expressed as means \pm standard error of the mean (SEM), and an alpha level of 0.05 was used as the criterion for statistical significance. Echocardiographic parameters between sham and HF rats were compared using unpaired $t$-tests.

We used the Multi Ontology Enrichment Tool (MOET) to explore functional categories of genes that were altered in HF within specific brain regions. MOET provides an unbiased analysis of groups of genes within each brain region that are functionally related, co-occur and are statistically enriched in a given gene population. To identify functional classes of genes that are statistically over-represented amongst the genes that are differentially expressed during HF, MOET uses the Gene Ontology (GO) consortium, which provides detailed annotations of genes with respect to their known or putative molecular function, cellular localization and biological processes (Smith et al., 2020). MOET provides a quantitative measurement of enrichment based on well accepted statistical methods including hypergeometric distributions to calculate p-values and correct the p-values with Holm-Bonferroni corrections and presents the number of genes involved in different annotations and the corresponding significance level in disease, pathway, biological, cellular and molecular ontologies. Four numbers are used to calculate each p-value

$$
\mathrm{p}=\underline{(M \text { choose } k)(N-M \text { choose } n-k)}
$$

$N$ choose $n$

where $n$ is the number of genes in our list, $N$ is the number of genes in the reference population, $k$ is the number of genes annotated with this item in our list and $M$ is the number of genes annotated with items in the reference population. The $p$-value was considered significant when $p<0.01$. The data that support the findings of this study are available from the corresponding author upon reasonable request.

\section{RESULTS}

\section{HF rats had severely reduced ejection fraction}

Figure 1 shows representative echocardiographic images from a Sham and HF rat and the mean heart function values obtained are shown in Table 1. Compared to Sham, HF rats showed a significant increase in the left ventricle diameter and volume during systole and diastole 
$(\mathrm{p}<0.0001)$ and a significant reduction in the left ventricle posterior and anterior thickness during systole $(\mathrm{p}<0.0001)$. Also, the HF rats exhibited a significant reduction in the percentage of fractional shortening and ejection fraction $(p<0.0001)$.

\section{HF rats displayed signs of polydipsia, anhedonia and increased anxiety}

Our results show that HF rats consumed more sucrose during the first sucrose exposure day when they were only given access to sucrose $(\mathrm{p}=0.018$; Fig. $2 \mathrm{~A}, \mathrm{n}=9$ and 7 for Sham and HF, respectively). More importantly, HF rats had a lower preference for sucrose on the preference test $(p=0.05$; Fig. $2 B)$ than Sham rats. When the rats were weighed and chow consumption and water intake were measured for $24 \mathrm{~h}$ after the SPT, HF rats consumed more water $(\mathrm{p}=0.02$; Figure 2C) than Sham rats, but had comparable chow intake ( $>00.05$; Fig. 2D) and body mass ( $>0.05$; Fig. 2E). Together, these studies indicate that HF rats ingested more fluids than Sham rats and that HF rats also had a significantly decreased preference for sucrose, which is a sign of anhedonia (Krishnan \& Nestler, 2011; Liu et al., 2018).

HF rats displayed several signs of anxiety in the EPM test $(n=12$ and 8 for Sham and HF, respectively). Specifically, HF rats spent less time in the open arms of the maze (p=0.048; Fig. $3 \mathrm{~A}$,$) , tended to make fewer entries into the open arms (\mathrm{p}=0.057$; Fig. 3B) and made more stretch attend attempts than Sham rats $(\mathrm{p}=0.041$; Fig. $3 \mathrm{C})$.

\section{HF rats had impaired spatial working memory and emotional, long-term memory}

In the SA task ( $\mathrm{n}=17$ and 13 for Sham and HF, respectively), HF rats made fewer alternations between arms ( $\mathrm{p}=0.026$; Fig. 4A), indicative of impaired spatial working memory. Although HF significantly disrupted the sequence of arm entries (i.e., percent alternation), it did not affect the number of arms the rats explored in the maze ( $\mathrm{p}>0.05$; Fig. 4B), suggesting that impaired alternation was not due to changes in activity levels.

On the IA retention test ( $\mathrm{n}=17$ and 12 for Sham and HF, respectively), HF rats displayed significantly shorter latencies to enter the compartment in which they had previously received shock than Sham rats $(\mathrm{p}=0.025$; Fig. $5 \mathrm{~A})$, a result that is indicative of impaired emotional, longterm memory. Of note, rats with HF did not have shorter latencies than Sham rats on the training day ( $>0.05$; Fig. 5B), suggesting that the HF-induced decreases in the retention latencies were not due to hyperactivity. 


\section{HF drastically downregulates the expression of several genes involved in synaptic plasticity in the PFC, PVN, CeA and DH}

To begin to identify potential molecular mechanisms underlying the HF-induced changes in mood and memory that we observed, we determined whether HF impacted expression of genes involved in synaptic plasticity in brain regions known to be critical neuronal substrates for mood and memory (i.e., PFC, DH, VH, BLA, and CeA) .We also included the PVN, a region that is wellestablished to play a major role in neurohumoral activation in this disease state, in which altered synaptic function and plasticity were described previously (Han et al., 2010; Potapenko et al., 2011; Potapenko et al., 2012, 2013; Stern \& Potapenko, 2013).

Given the extensive number of genes sampled in the array, and in order to prioritize for further validation and interpretation those genes that were more robustly affected, we set a qualitative and arbitrary threshold of a $+/-40 \%$ change in expression. Using this criterion, we generated a heatmap graph (Figure 6A) that exhibits the profile of genes whose expression were robustly upregulated ( $\geq+40 \%$ change, in blue range color), downregulated ( $\leq+40 \%$ change, in red range color), or showed no changes (white rectangles) in expression when comparing HF to sham rats across the six different brain regions. Figure $6 \mathrm{~B}$ provides a summary of the main changes observed by brain region. Overall, the results showed a drastic HF-induced downregulation of synaptic plasticity-related genes compared to Sham rats, with $\sim 87 \%$ of genes showing a downregulation ( $\leq+40 \%$ in expression) in at least one brain region. Conversely, increased expression ( $\geq+40 \%$ in expression) was observed only in $\sim 5 \%$ of genes tested. The PFC and PVN exhibited the largest number of down regulated genes during $\mathrm{HF}$, with $\sim 80 \%$ and $\sim 54 \%$ genes decreased, respectively. A milder change was observed in the $\mathrm{DH}$ and CeA, where HF downregulated $\sim 20 \%$ of genes tested compared to Sham rats. Lastly, HF had minimal effects on synaptic plasticity genes in the BLA and VH, with less than $10 \%$ of genes being altered (Fig. 6B). Interestingly, the few genes that showed increases were mostly (3/4 genes, $75 \%)$ restricted to the VH.

HF downregulated several important groups of genes, including IEGs (activity-regulated cytoskeletal -associated protein [Arc; aka Arg3.1], the Egr family of zinc fingered transcription factors, and Jun), genes encoding for glutamate receptors, predominantly metabotropic receptors (Grm 1, -2, -3, -4, -5, -7), but also ionotropic NMDA receptor subunits (Grin2a and Grin2b). HF 
also downregulated various types of protein phosphatases (Ppplcc and Ppp2ca) and protein kinases (Prkca, Prkcg and Prkgl) in the PFC and PVN. Figure 6C depicts genes grouped according to the number of brain areas in which they were impacted, with genes changing in four to five brain areas grouped in Cluster $1(\mathrm{C} 1)$, three in Cluster 2 (C2), two in Cluster 3 (C3) and only one brain area in Cluster 4 (C4). The genes whose expression changed in most of the brain regions tested during HF included Arc, Adcyl (type 1 adenylyl cyclase), Grm2 and Grm5, and the protoproto-oncogene serine/threonine-protein kinase Pim-1 (Pim1; see C1). Interestingly, another gene directly associated to metabotropic glutamate receptor (mGluR) function and synaptic plasticity, Homerl (Fig. 6A, light green cluster), was also downregulated during HF in the PFC, PVN and CeA. Cyclic adenosine monophosphate (cAMP) responsive element binding protein 1 gene (Crebl), a gene critically linked to vascular dementia, learning, memory and cognitive abilities (Brightwell et al., 2004; Sadamoto et al., 2010; Han et al., 2018), was also reduced by HF in the PFC, PVN and DH (Fig. 6A, purple cluster).

We then used the Multi Ontology Enrichment Tool (MOET), which provides an unbiased analysis of groups of genes within each brain region that are functionally related, co-occur and are statistically enriched in a given gene population. MOET uses the Gene Ontology (GO) consortium, in order to identify functional classes of genes that are statistically over-represented amongst the genes that are differentially expressed during HF (Smith et al., 2020). For this analysis, we focused on the PFC, $\mathrm{DH}$ and $\mathrm{CeA}$, which are the three brain regions that showed the most significant changes in gene expression and are implicated in the measures of mood and memory used in our experiments (see Fig.7; results from the PVN and VH are shown in Supplementary Fig.1. Note that MOET was not applied to BLA given that only 1 gene changed in this region). We highlight two major groups of GOs related to (1) biological, cellular and/or molecular pathways/functions (left graphs, 7A, C and E) and (2) disease-related processes (right graphs, 7B, D and F). For simplicity and relevance, only the GO subcategories in which the gene counts represented $50 \%$ or more of the total genes associated with that GO that were down- or upregulated during HF, and that were considered statistically significant by MOET are displayed.

For the first major group of GOs (Fig. 7A, C and E), the MOET analysis revealed that multiple genes that were robustly downregulated during HF are involved in cell communication, cell-cell signaling, cellular response to stimulus and synaptic structure/function/modulation, particularly for glutamatergic synapses (Fig. 7A and C, written in green). In addition, there was a 
notable involvement of genes involved in cellular metabolic processes and intracellular organelles. Interestingly, an involvement for genes related to learning and memory and cognition was observed to occur only in the DH (Fig. 7C). For the GOs related to disease processes (Fig. 7B, D and F), there was an enriched involvement of multiple genes across the three brain regions, which are associated with CNS diseases, diseases of mental health, as well as cognitive disorders. Importantly, the three regions also displayed involvement of genes involved in cardiovascular/vascular diseases. Finally, and perhaps somewhat surprising, an involvement of genes related to cancer/neoplasms was also observed.

In order to independently validate our PCR array data, we performed qRT-PCR using individual primers for five genes, Adcyl, Arc, Homerl, Mapkl and Nr4al, with B2m as the housekeeping gene (see Fig. 8). In all cases, the qRT-PCR replicated the direction of the PCR array results (i.e., increase, decrease or no effects), although the magnitude did not match precisely. For example, the results with the individual primers showed that HF significantly downregulated Adcyl in the PFC (-1.30), PVN (-1.54), CeA (-1.49), DH (-1.48), and BLA (-1.12), but upregulated it in the VH (1.52), (Fig. 8A), which is the same pattern that we observed in the PCR array (Fig. 8B). A similar profile of results was observed for the individual primers and array for Arc, Homerl, Mapkl and Nr4al (Fig. 8A and B). 


\section{DISCUSSION}

Collectively, the present findings show that a rat model of HF characterized by severely reduced ejection fraction disrupts several behavioral measures of mood and memory and drastically alters the pattern of synaptic plasticity-associated gene expression in brain areas critical for mood and memory. Specifically, we found that HF decreased sucrose preference, which is a sign of anhedonia, and increased measures of anxiety in the EPM. HF also impaired SA and IA retention performance, indicating that HF disrupts spatial working memory and emotional, longterm memory, respectively.

Although both clinical and experimental studies in animal models support a link between HF and cognitive/mood impairments, (Rutledge et al., 2006; Angermann et al., 2012; Lossnitzer et al., 2013; Cameron et al., 2014; Cannon et al., 2017; Toledo et al., 2019; Wang et al., 2019), the precise mechanisms and molecular underpinnings remain elusive. Cognitive impairment in neurodegenerative disorders and aging, as well as mood disorders have been linked to altered synapse structure/functional properties as well as to deficits in synaptic plasticity mechanisms including blunted LTP. Thus, in order to gain insights into possible molecular underpinnings of cognitive and mood disorders in HF, we conducted a PCR array study that assessed the simultaneous expression of 84 genes critical for synaptic plasticity. Importantly, our findings showed that HF drastically downregulated numerous genes implicated in synaptic plasticity in a brain region-dependent manner, with the most profound changes observed in PVN and PFC, moderate changes in $\mathrm{DH}$ and $\mathrm{CeA}$, and minimal alterations in $\mathrm{VH}$ and BLA.

To the best of our knowledge, the present results are the first to show that HF impairs SA and IA. Both memory tasks are dependent on the integrity of DH (Quevedo et al., 1997; Izquierdo et al., 2000; Dickson et al., 2007; Sakaguchi \& Sakurai, 2020) and PFC (Delatour \& GisquetVerrier, 1996; Giovannini et al., 2005; Torkaman-Boutorabi et al., 2015; Woloszynowska-Fraser et al., 2017), which are interconnected brain regions critical for memory. IA is also dependent on an intact VH, CeA, and BLA (Parent et al., 1992; Roozendaal \& McGaugh, 1997; Giovannini et al., 2005; Nobre, 2013), which may account for the finding that HF-induced memory loss appeared more pronounced in the IA task than in SA. Collectively, the findings show that our animal model of HF impacts both working memory (i.e., SA) and long-term memory (i.e., IA), which is 
consistent with findings showing that rats with severely reduced ejection fraction have impaired long-term memory in the spatial water maze (Lu et al., 2020) and with results showing that HF patients have deficits in both immediate and delayed recall (Leto \& Feola, 2014). Short-term memory deficits appear to be one of the most pervasive cognitive issues in HF, which is significant because these problems are associated with impaired ability for HF patients to manage their medical condition (Gaviria et al., 2011; Leto \& Feola, 2014).

The present findings are consistent with previous research showing that HF decreases sucrose preference and increases anxiety in the EPM (Prickaerts et al., 1996; Lu et al., 2017; Najjar et al., 2018b; Liu et al., 2019; Wang et al., 2019). The present results extend those findings by showing that these effects are observed in a rat model of HF characterized by severely reduced ejection fraction. Moreover, our gene array findings suggest that these effects are likely due to PFC dysfunction, given that manipulations that inhibit PFC produce anhedonia (Banasr \& Duman, 2008; Kabir et al., 2017) and increase anxiety (de Visser et al., 2011).

Both the amygdala and the PVN are important neuronal substrates implicated in the regulation of mood, and recent studies support that a direct connection from the PVN to the amygdala modulates anxiety levels and fear memories (Knobloch et al., 2012; Hasan et al., 2019). Moreover, changes in proper neuronal function within the amygdala could contribute to the anxiogenic effect observed in HF rats (Lisboa et al., 2010; Tye et al., 2011; Strauss et al., 2013; Ventura-Silva et al., 2013; Sorregotti et al., 2018; Pi et al., 2020). Still, it is yet unclear whether the changes in gene expression reported in this study in the CeA, BLA and PVN could be directly related to the mood disorders reported in HF rats.

Our findings indicate that HF increases water intake, which is in agreement with a previous report indicating that myocardial infarction in rats and mice increase thirst (De Smet et al., 2003; Frey et al., 2014) and with evidence showing that excessive thirst is a common symptom observed in patients with HF (Allida et al., 2015). This increase in thirst is likely due to chronic activation of the systemic and central angiotensin II signaling (Prager et al., 2016) and/or increases in circulating levels of arginine vasopressin (Kheirbek et al., 2012) that are both hallmarks of HF. Importantly, the PVN is a critical component of the neural circuitry that underlies thirst (Cohn et al., 1984; Krishnan \& Nestler, 2011; Dardiotis et al., 2012; Dobryakova et al., 2017) and our PCR gene array findings indicate that HF induces a massive decrease in gene expression in PVN. 
Our findings show a drastic downregulation of multiple genes implicated in synaptic plasticity in a brain region-dependent manner in rats with HF compared to sham controls. For instance, changes in genes involved in learning and memory were observed only in DH and not in CeA or PFC. This may reflect the different role of these brain areas in cognition. DH involvement in SA and IA is assumed to reflect an episodic (i.e., autobiographical) memory of where the animal has been (i.e., SA) and the context in which it received footshock (i.e., IA). In contrast, the amygdala's role in IA may be more related to the emotional component of the task (Roozendaal et al., 2009; Janak \& Tye, 2015; Bocchio et al., 2017) and PFC may be necessary for SA and IA due to its critical role in executive function and decision-making (Goldman-Rakic, 1996). Although spatial abilities and episodic memory appear to be the most compromised cognitive functions in HF (Hjelm et al., 2012), HF patients do also show impaired executive function (Pressler et al., 2010b; Harkness et al., 2011; Dardiotis et al., 2012).

The present results appear to be the first to show that HF impacts amygdala-dependent memory (i.e., IA) and significantly decreases the expression of several genes critical for synaptic plasticity in $\mathrm{CeA}$, while minimally impacting another region of the amygdala implicated in mood and memory (i.e., BLA). To date, there is very limited evidence implicating the amygdala in any effects of HF in human patients or animal models. In patients, HF is associated with reduced blood flow to amygdala (Roy et al., 2017) and increased amygdala responses to sympathetic activation (Woo et al., 2005; Etkin \& Wager, 2007). In animal models, HF increases glial density (GFAP immunoreactivity) in the medial amygdala, which is critical for cardiovascular reflexes and central control of sympathetic responses (Salazar et al., 2014). HF also decreases orexin type 2 receptor gene expression in amygdala, although whether this decrease is restricted to a particular amygdala nucleus is unknown (Hayward et al., 2015). Thus, the present results significantly advance our understanding of the consequences of HF by showing that HF characterized by a severe reduction in ejection fraction is associated with the downregulation of several genes in CeA and a relative sparing of BLA.

Our findings show that HF impacts DH expression but has minimal effect on VH, which is consistent with extensive evidence indicating that the hippocampus is not a unitary structure and that there are clear distinctions between $\mathrm{DH}$ and $\mathrm{VH}$. For example, DH and VH have different anatomical connections, cellular and circuit properties and patterns of gene expression that likely contribute to the different functions that they serve (Moser \& Moser, 1998; Thompson et al., 2008; 
Dong et al., 2009; Barkus et al., 2010; Fanselow \& Dong, 2010; Bienkowski et al., 2018). DH appears to be primarily responsible for the cognitive functions of the hippocampus (Moser \& Moser, 1998; Sahay \& Hen, 2007; Barkus et al., 2010; Fanselow \& Dong, 2010), which is consistent with our finding that that genes associated with learning and memory were only impacted in DH. Our findings also add to evidence suggesting that $\mathrm{DH}$ is more vulnerable to neuroinflammation and other pathology than VH (Fuster-Matanzo et al., 2011; Stouffer et al., 2015; Dobryakova et al., 2017; Dobryakova et al., 2019; Tournier et al., 2019).

Several critical families of genes were considerably affected in these brain regions in HF rats. These include various IEGs, such as Arc, Egr, Jun (but not Fos), which would suggest an overall reduction in neuronal activation in these areas, which could be a result of reduced inputs from upstream brain regions. Another major group of genes downregulated during HF were genes encoding glutamate receptors, predominantly metabotropic, but also ionotropic AMPA and NMDA receptor subunits. Given the importance of glutamate receptor signaling in maintaining appropriate basal network activity levels, as well as a playing a critical role in both up- and downregulation of the strength of synaptic efficacy (e.g., LTP and LTD) (Park et al., 2008; Waung et al., 2008; Crupi et al., 2019), it would be expected that the reported changes in GLURs may also contribute to lower levels of neuronal activation and compromised synaptic plasticity in HF rats. Other major gene families downregulated during HF included neurotrophic factors (e.g., BDNF, Ntrk2 and Ngf) and kinases and phosphatases (e.g., Ppp1cc, Ppp2ca, Prkca, Prkcg and Prkg1).

We used MOET to identify functional categories among the genes altered in HF within specific brain regions, which provides an unbiased analysis of groups of genes that are functionally related and that co-occurr and/or are co-affected during a specific condition (e.g., HF). For simplicity, we focused on two major Gene Ontology categories (GOs): (1) biological/molecular pathways and (2) disease-related processes. As summarized in Fig.7, the MOET analysis revealed that the majority of genes downregulated during HF were functionally related and are involved in cell communication, cellular response to stimulus, dendritic signaling, and synaptic structure/function/modulation, particularly for glutamatergic synapse. More importantly, MOET also revealed that multiple genes that changed across brain regions were associated with diseases of mental health, cognitive disorders as well as cardiovascular/vascular diseases. This is in agreement with multiple previous publications supporting that downregulation of several of the 
same genes we found in HF have been linked to cognitive dysfunction and neurodegenerative diseases such as Alzheimer's Disease (Wong et al., 1999; Guzowski et al., 2000; Wang et al., 2004; Plath et al., 2006; Park et al., 2008; Waung et al., 2008; Davis et al., 2010; Velazquez et al., 2016; Wilkerson et al., 2018).

Numerous putative mechanisms, not mutually exclusive, could contribute to the disruption of the molecular underpinnings of synaptic plasticity during HF. One obvious candidate is neuroinflammation, a hallmark pathophysiological phenomenon in HF (Diaz et al., 2020). Activation of neuroinflammatory pathways within the hypothalamic PVN has been directly implicated as an underlying mechanism contributing to sympathohumoral activation in this disease (Kang et al., 2008; Xu \& Li, 2015; Yu et al., 2018). Importantly, findings in rodents have implicated neuroinflammation and the expression of inflammatory and signal transduction genes in HF-induced cognitive impairment, depression and anxiety-like behavior (Frey et al., 2014; Hay et al., 2017; Toledo et al., 2019; Wang et al., 2019). This possibility is supported by evidence showing that HF impacts the expression of genes related to inflammation in the hippocampus and PFC of mice (Frey et al., 2014).

Another critical pathophysiological mechanism in HF is cerebral hypoperfusion associated with low cardiac output that chronically leads to brain ischemia and microinfarcts (Celutkiene et al., 2016). In fact, several clinical studies implicate compromised cerebral blood flow as a mechanism contributing to cognitive impairment and dementia in patients with HF (Pullicino \& Hart, 2001; Zuccala et al., 2001; Iadecola, 2013). It is noteworthy that hypoxia reduces the expression of genes that are required for the maintenance of synaptic structure and function (Bazan et al., 2002), and several of the key genes found to be disrupted in HF in this study, including Arc, Egr and mGLURs were previously reported to be affected by hypoxia (Simonyi et al., 1999; Hong et al., 2003; Martin et al., 2012; Zhao et al., 2012; Alagappan et al., 2013; Chan et al., 2016; Chen et al., 2016; Su et al., 2020). Of particular interest to this study, Arc expression in the hippocampus was shown to be significantly downregulated following ischemic conditions, both in vitro and in vivo (Hong et al., 2003). Moreover, manipulations that increase Arc expression protected against hypoxia-related cognitive impairment and hippocampal damage (Zeng et al., 2019). Whether chronic brain hypoperfusion and/or neuroinflammation contribute to the disruption of molecular underpinnings of synaptic plasticity and cognitive and mood disorders in HF remains to be determined. 
An important limitation of our studies is that they were focused exclusively on male rats. We chose to use males given the fact that most previous studies assessing the contribution of the hypothalamus to neurohumoral activation in the HF rat model, including our own (Biancardi et al., 2011; Potapenko et al., 2011; Potapenko et al., 2012, 2013; Stern \& Potapenko, 2013; FerreiraNeto et al., 2017; Ferreira-Neto \& Stern, 2019), as well as those focusing on HF-associated neuroinflammation (Kang et al., 2008; Xu \& Li, 2015; Yu et al., 2018), were conducted in male rats. Nonetheless, given that the incidence of HF and cognitive/mood comorbidities are sexdependent (Gottlieb et al., 2004; Rutledge et al., 2006; Najjar et al., 2018a), it is plausible that the behavioral and molecular changes reported here are sex-dependent as well.

Collectively, the present findings suggest that the impaired mood and cognition observed in HF patients that is associated with higher hospital readmission and mortality rates (Dickson et al., 2007; Pressler et al., 2010a; Lee et al., 2013; Lossnitzer et al., 2013) is likely due be due to pathology in DH and PFC. This interpretation is in accordance with the finding that learning and working memory deficits, delayed recall, depression, and anxiety are correlated with significant cerebral grey matter loss in hippocampus and PFC (Almeida et al., 2012; O'Donnell et al., 2012). Moreover, our findings suggest that the amygdala, particularly CeA, also contributes to mood and memory problems in HF. The present findings provide support for the fact that HF is not only a neurohumoral cardiovascular problem but is also a disorder of mood and memory. Moreover, our data also indicate that HF is associated with a drastic downregulation of several critical genes implicated in synaptic plasticity in brain areas necessary for cognitive, mood and homeostatic processes, suggesting that they could underlie the effects of HF on mood and memory. 


\section{ADDITIONAL INFORMATION}

\section{COMPETING INTERESTS}

All authors acknowledge that they there are no conflict of interests to disclose in accordance with the Journal policy.

\section{AUTHOR CONTRIBUTIONS}

ARK conducted behavioral testing, data analyses and drafted portions of the manuscript; SK and KEW conducted behavioral testing and scoring and contributed to the literature review; HCFN performed HF surgeries, echocardiographic studies, brain punches, RNA extraction, array and qRT-PCR experiments and analysis, drafted the manuscript; FA performed brain punches for the array and qRT-PCR experiments; AAP and DNC contributed to the design, analysis, interpretation, figure construction and initial draft of the gene array and qRT-PCR data; MBP and JES designed the study, supervised experiments and drafted and edited the manuscript. All authors critically reviewed the manuscript and approved the final version for publication.

\section{FUNDING}

This work was supported by a National Heart, Lung, and Blood Institute Grant NIH R01HL090948 (Stern JE), a National Institute of Diabetes and Digestive and Kidney Diseases Grant NIH R01DK114700 (Parent MB), a National Institute of Neurological Disorders and Stroke Grant NIH R01NS115209 (Cox DN), a GSU Brains and Behavior seed grant (Stern JE and Parent MB), and a DFG Postdoc Fellowship AL 2466/1-1 (Althammer F). 


\begin{tabular}{|c|c|c|}
\hline & Sham & $\mathrm{HF}$ \\
\hline LVID,d (mm) & $7.98 \pm 0.18$ & $10.68 \pm 0.20^{* * * *}$ \\
\hline LVPW,d (mm) & $2.13 \pm 0.11$ & $2.02 \pm 0.17$ \\
\hline LVAW,d (mm) & $1.97 \pm 0.05$ & $2.02 \pm 0.12$ \\
\hline LV Vol,d $(\mu L)$ & $347.34 \pm 17.05$ & $659.89 \pm 27.97^{* * * *}$ \\
\hline LVID,s (mm) & $3.84 \pm 0.17$ & $9.19 \pm 0.21^{\star * \star *}$ \\
\hline LVPW,s (mm) & $3.41 \pm 0.13$ & $2.18 \pm 0.16^{* * * *}$ \\
\hline LVAW,s (mm) & $3.49 \pm 0.08$ & $2.62 \pm 0.15^{\star * * *}$ \\
\hline LV Vol,s $(\mu \mathrm{L})$ & $68.35 \pm 6.69$ & $476.95 \pm 24.40^{\star * * *}$ \\
\hline EF \% & $81.02 \pm 1.39$ & $28.08 \pm 1.55^{\star * * *}$ \\
\hline FS \% & $52.19 \pm 1.50$ & $14.08 \pm 0.84^{* * * *}$ \\
\hline
\end{tabular}

Table 1. Summary data of echocardiography measurements of left ventricular parameters obtained from Sham and HF rats. Values are expressed as means \pm SEM; Sham $n=21$; HF $n=$ 27. LVID, $\mathrm{d}$ and $\mathrm{s}$ : left ventricle internal dimension during diastole and systole; LVAW, $\mathrm{d}$ and s: left ventricle anterior wall thickness during diastole and systole; LVPW, $d$ and s: left ventricle posterior wall thickness during diastole and systole; LV Vol, $\mathrm{d}$ and s: left ventricle volume during diastole and systole; EF, ejection fraction; FS, fractional shortening. ${ }^{* * * *}$ p $<0.0001$ vs. Sham. 


\section{FIGURE LEGENDS}

Figure 1. HF rats displayed severely reduced left ventricular function. Representative echocardiograph images of the movement-mode, short-axis view from a Sham (A) and a Heart Failure (HF) rat (B). AW, anterior wall; PW, posterior wall; LV, left ventricle; LVID, d/s: left ventricle internal diameter in diastole and systole.

Figure 2. HF produced polydipsia and anhedonia. (A) In the sucrose preference test, HF rats consumed more sucrose than Sham controls during the first exposure day when they were only offered sucrose, but more importantly had a (B) decreased preference for sucrose on the sucrose preference testing day. (C) During a subsequent $24 \mathrm{~h}$ period, HF rats consumed more water than Sham rats, but had comparable chow intake (D) and body mass (E). ${ }^{*} p<0.05$ vs. Sham.

Figure 3. HF increases anxiety and risk assessment. (A) In the EPM, HF rats spent significantly less per cent time in the open arms, (B) tended to make fewer per cent entries into the open arms and (C) made more stretch attend attempts. ${ }^{*} p<0.05$ and $\# p=0.057$ vs. Sham.

Figure 4. HF impairs spatial working memory without affecting activity levels. (A) In the SA test, HF rats made significantly fewer alternations between arms, but (B) entered a comparable number of arms. ${ }^{*} \mathrm{p}<0.05$ vs. Sham.

Figure 5. HF impairs emotional, long-term memory (A) In the IA task, HF rats entered the dark/shock compartment more quickly than Sham rats on the retention test, (B) but their latencies did not differ during training. ${ }^{*} \mathrm{p}<0.05$ vs. Sham.

Figure 6. HF significantly alters synaptic plasticity-related gene expression. (A) Heatmap graph showing the level of expression of different genes regulated by HF in relation to sham rats' gene expression. Downregulation below $40 \%$ change is shown in the red range, upregulation above $40 \%$ change is shown in the blue range and the expression of genes that did not change below or above $40 \%$ is shown in white. Adcyl, Arc, Homerl, Mapkl and Nr4al, the genes used for the 
qPCR validation, are in bold. (B) Bar graph showing the percentage of genes that were upregulated (blue), downregulated (red), or did not change (white) during HF in PFC, PVN, DH, CeA, BLA and VH. (C1-C4) Heatmap graphs depicting clusters of genes that were upregulated (blue), downregulated (red) or not affected (white) due to heart failure. Clusters are organized according to genes that changed with HF vs. Sham in four to five brain areas (C1); three brain areas (C2); two brain areas $(\mathbf{C 3})$ or only one brain area $(\mathbf{C 4})$. Categories written in: red represents Egr family; green represents Gria family; purple represents Grm family; orange represents kinases and phosphatases related genes.

Figure 7. Quantitative ontology analysis of gene expression in the PFC, DH and CeA of HF rats. (A,C,E), Summary bar graphs showing the analysis of biological, cellular or molecular gene ontologies (GOs) terms that are significantly enriched based on the number of genes that were upor downregulated in HF rats vs. Sham in $\operatorname{PFC}(\mathbf{A}), \mathrm{DH}(\mathbf{C})$ and $\mathrm{CeA}(\mathbf{E})$. (B,D,F) Summary bar graphs showing the analysis of disease ontology terms highlighting important disease categories that involve the up- or downregulated genes by HF in PFC (B), DH (D) and CeA (F). Categories written in red represent those enriched terms that show up in PFC, DH and CeA; green represents those that show up in PFC and DH; blue represents those that show up in PFC and CeA; and orange represents those that show up in DH and CeA. All the categories included in the graphs reached statistical significance $\mathrm{p}<0.00001$.

Figure 8. qRT-PCR validation of results obtained in the gene array study. (A), Summary bar graphs showing the mean fold change in mRNA levels for Adcyl, Arc, Homer1, Mapk1 and Nr4al genes in HF rats in relation to Sham rats (theoretical mean $=+/-1$ ) in the PFC (black bars), PVN (red bars), CeA (blue bars), BLA (green bars), DH (orange bars) and VH (purple bars). Dashed lines indicate the theoretical means. (B), heatmap graph showing the magnitude of change in gene expression in the array and validation shown as fold change in gene expression from -2.39 to +2.39 induced by HF in relation to sham rats' gene expression. ${ }^{*} \mathrm{p}<0.05, * * \mathrm{p}<0.01$ and $* * * \mathrm{p}<0.001$ vs. theoretical mean, one sample t-test.

\section{Supplementary Figure 1. Qualitative ontology analysis of gene expression in the PVN and}

VH of HF rats. (A) and (C), summary bar graphs showing the analysis of biological, cellular or 
molecular ontologies (GO) displaying critical biological processes categories that involves the upor downregulated genes by HF in PVN (A) and DH (C). (B) and (D), summary bar graphs showing the analysis of disease ontology (GO) highlighting important disease categories that involves the up- or downregulated genes by HF in PVN (B) and DH (D). All the categories in included in the graphs reached statistical significance $\mathrm{p}<0.00001$, test used. 


\section{REFERENCES}

\section{Uncategorized References}

Alagappan D, Balan M, Jiang Y, Cohen RB, Kotenko SV \& Levison SW. (2013). Egr-1 is a critical regulator of EGF-receptor-mediated expansion of subventricular zone neural stem cells and progenitors during recovery from hypoxia-hypoglycemia. ASN Neuro 5, 183-193.

Allida SM, Inglis SC, Davidson PM, Lal S, Hayward CS \& Newton PJ. (2015). Thirst in chronic heart failure: a review. J Clin Nurs 24, 916-926.

Almeida OP, Garrido GJ, Beer C, Lautenschlager NT, Arnolda L \& Flicker L. (2012). Cognitive and brain changes associated with ischaemic heart disease and heart failure. Eur Heart J 33, 1769-1776.

Ambrosy AP, Gheorghiade M, Chioncel O, Mentz RJ \& Butler J. (2014). Global perspectives in hospitalized heart failure: regional and ethnic variation in patient characteristics, management, and outcomes. Curr Heart Fail Rep 11, 416-427.

Angermann CE, Frey A \& Ertl G. (2012). Cognition matters in cardiovascular disease and heart failure. Eur Heart J 33, 1721-1723.

Banasr M \& Duman RS. (2008). Glial loss in the prefrontal cortex is sufficient to induce depressivelike behaviors. Biol Psychiatry 64, 863-870.

Bannerman DM, Rawlins JN, McHugh SB, Deacon RM, Yee BK, Bast T, Zhang WN, Pothuizen HH \& Feldon J. (2004). Regional dissociations within the hippocampus--memory and anxiety. Neurosci Biobehav Rev 28, 273-283.

Barkus C, McHugh SB, Sprengel R, Seeburg PH, Rawlins JN \& Bannerman DM. (2010). Hippocampal NMDA receptors and anxiety: at the interface between cognition and emotion. Eur J Pharmacol 626, 49-56.

Bazan NG, Palacios-Pelaez R \& Lukiw WJ. (2002). Hypoxia signaling to genes: significance in Alzheimer's disease. Mol Neurobiol 26, 283-298.

Belleau EL, Treadway MT \& Pizzagalli DA. (2019). The Impact of Stress and Major Depressive Disorder on Hippocampal and Medial Prefrontal Cortex Morphology. Biol Psychiatry 85, 443-453.

Benjamin EJ, Muntner $P$, Alonso A, Bittencourt MS, Callaway CW, Carson AP, Chamberlain AM, Chang AR, Cheng S, Das SR, Delling FN, Djousse L, Elkind MSV, Ferguson JF, Fornage M, Jordan LC, Khan SS, Kissela BM, Knutson KL, Kwan TW, Lackland DT, Lewis TT, Lichtman 
JH, Longenecker CT, Loop MS, Lutsey PL, Martin SS, Matsushita K, Moran AE, Mussolino ME, O'Flaherty M, Pandey A, Perak AM, Rosamond WD, Roth GA, Sampson UKA, Satou GM, Schroeder EB, Shah SH, Spartano NL, Stokes A, Tirschwell DL, Tsao CW, Turakhia MP, VanWagner LB, Wilkins JT, Wong SS, Virani SS, American Heart Association Council on E, Prevention Statistics C \& Stroke Statistics S. (2019). Heart Disease and Stroke Statistics2019 Update: A Report From the American Heart Association. Circulation 139, e56-e528.

Biancardi VC, Son SJ, Sonner PM, Zheng H, Patel KP \& Stern JE. (2011). Contribution of central nervous system endothelial nitric oxide synthase to neurohumoral activation in heart failure rats. Hypertension 58, 454-463.

Bienkowski MS, Bowman I, Song MY, Gou L, Ard T, Cotter K, Zhu M, Benavidez NL, Yamashita S, Abu-Jaber J, Azam S, Lo D, Foster NN, Hintiryan H \& Dong HW. (2018). Integration of gene expression and brain-wide connectivity reveals the multiscale organization of mouse hippocampal networks. Nat Neurosci 21, 1628-1643.

Bird CM. (2017). The role of the hippocampus in recognition memory. Cortex 93, 155-165.

Bocchio M, Nabavi S \& Capogna M. (2017). Synaptic Plasticity, Engrams, and Network Oscillations in Amygdala Circuits for Storage and Retrieval of Emotional Memories. Neuron 94, 731743.

Brightwell JJ, Gallagher M \& Colombo PJ. (2004). Hippocampal CREB1 but not CREB2 is decreased in aged rats with spatial memory impairments. Neurobiol Learn Mem 81, 19-26.

Cameron J, Pressler SJ, Ski CF \& Thompson DR. (2014). Cognitive impairment in heart failure: towards a consensus on screening. Eur J Heart Fail 16, 235-237.

Cannon JA, Moffitt P, Perez-Moreno AC, Walters MR, Broomfield NM, McMurray JJV \& Quinn TJ. (2017). Cognitive Impairment and Heart Failure: Systematic Review and Meta-Analysis. J Card Fail 23, 464-475.

Celutkiene J, Vaitkevicius A, Jakstiene S \& Jatuzis D. (2016). Expert Opinion-Cognitive Decline in Heart Failure: More Attention is Needed. Card Fail Rev 2, 106-109.

Chan YL, Saad S, Pollock C, Oliver B, Al-Odat I, Zaky AA, Jones N \& Chen H. (2016). Impact of maternal cigarette smoke exposure on brain inflammation and oxidative stress in male mice offspring. Sci Rep 6, 25881.

Chen X, Liu Y, Zhang Z, Miao X, Tian Y, Yao L, Liu J, Lu H \& Liu Y. (2016). Hypoxia stimulates the proliferation of rat neural stem cells by regulating the expression of metabotropic glutamate receptors: an in vitro study. Cell Mol Biol (Noisy-le-grand) 62, 105-114. 
Cohn JN, Levine TB, Francis GS \& Goldsmith S. (1981). Neurohumoral control mechanisms in congestive heart failure. Am Heart J 102, 509-514.

Cohn JN, Levine TB, Olivari MT, Garberg V, Lura D, Francis GS, Simon AB \& Rector T. (1984). Plasma norepinephrine as a guide to prognosis in patients with chronic congestive heart failure. N Engl J Med 311, 819-823.

Cole J, Costafreda SG, McGuffin P \& Fu CH. (2011). Hippocampal atrophy in first episode depression: a meta-analysis of magnetic resonance imaging studies. J Affect Disord 134, 483-487.

Crupi R, Impellizzeri D \& Cuzzocrea S. (2019). Role of Metabotropic Glutamate Receptors in Neurological Disorders. Front Mol Neurosci 12, 20.

Dardiotis E, Giamouzis G, Mastrogiannis D, Vogiatzi C, Skoularigis J, Triposkiadis F \& Hadjigeorgiou GM. (2012). Cognitive impairment in heart failure. Cardiol Res Pract 2012, 595821.

Davis M, Walker DL, Miles L \& Grillon C. (2010). Phasic vs sustained fear in rats and humans: role of the extended amygdala in fear vs anxiety. Neuropsychopharmacology 35, 105-135.

De Smet HR, Menadue MF, Oliver JR \& Phillips PA. (2003). Increased thirst and vasopressin secretion after myocardial infarction in rats. Am J Physiol Regul Integr Comp Physiol 285, R1203-1211.

de Visser L, Baars AM, van 't Klooster J \& van den Bos R. (2011). Transient inactivation of the medial prefrontal cortex affects both anxiety and decision-making in male wistar rats. Front Neurosci 5, 102.

Delatour B \& Gisquet-Verrier P. (1996). Prelimbic cortex specific lesions disrupt delayed-variable response tasks in the rat. Behav Neurosci 110, 1282-1298.

Diaz HS, Toledo C, Andrade DC, Marcus NJ \& Del Rio R. (2020). Neuroinflammation in heart failure: new insights for an old disease. J Physiol 598, 33-59.

Dickson VV, Tkacs N \& Riegel B. (2007). Cognitive influences on self-care decision making in persons with heart failure. Am Heart J 154, 424-431.

Dillon GM, Qu X, Marcus JN \& Dodart JC. (2008). Excitotoxic lesions restricted to the dorsal CA1 field of the hippocampus impair spatial memory and extinction learning in C57BL/6 mice. Neurobiol Learn Mem 90, 426-433.

Dixon ML, Thiruchselvam R, Todd R \& Christoff K. (2017). Emotion and the prefrontal cortex: An integrative review. Psychol Bull 143, 1033-1081. 
Dobryakova YV, Kasianov A, Zaichenko MI, Stepanichev MY, Chesnokova EA, Kolosov PM, Markevich VA \& Bolshakov AP. (2017). Intracerebroventricular Administration of (192) IgG-Saporin Alters Expression of Microglia-Associated Genes in the Dorsal But Not Ventral Hippocampus. Front Mol Neurosci 10, 429.

Dobryakova YV, Volobueva MN, Manolova AO, Medvedeva TM, Kvichansky AA, Gulyaeva NV, Markevich VA, Stepanichev MY \& Bolshakov AP. (2019). Cholinergic Deficit Induced by Central Administration of 192IgG-Saporin Is Associated With Activation of Microglia and Cell Loss in the Dorsal Hippocampus of Rats. Front Neurosci 13, 146.

Dong HW, Swanson LW, Chen L, Fanselow MS \& Toga AW. (2009). Genomic-anatomic evidence for distinct functional domains in hippocampal field CA1. Proc Natl Acad Sci U S A 106, 11794-11799.

Ekstrom AD \& Ranganath C. (2018). Space, time, and episodic memory: The hippocampus is all over the cognitive map. Hippocampus 28, 680-687.

Etkin A \& Wager TD. (2007). Functional neuroimaging of anxiety: a meta-analysis of emotional processing in PTSD, social anxiety disorder, and specific phobia. Am J Psychiatry 164, 1476-1488.

Fanselow MS \& Dong HW. (2010). Are the dorsal and ventral hippocampus functionally distinct structures? Neuron 65, 7-19.

Ferreira-Neto HC, Biancardi VC \& Stern JE. (2017). A reduction in SK channels contributes to increased activity of hypothalamic magnocellular neurons during heart failure. J Physiol 595, 6429-6442.

Ferreira-Neto HC \& Stern JE. (2019). Functional coupling between NMDA receptors and SK channels in rat hypothalamic magnocellular neurons: altered mechanisms during heart failure. J Physiol.

Frey A, Popp S, Post A, Langer S, Lehmann M, Hofmann U, Siren AL, Hommers L, Schmitt A, Strekalova T, Ertl G, Lesch KP \& Frantz S. (2014). Experimental heart failure causes depression-like behavior together with differential regulation of inflammatory and structural genes in the brain. Front Behav Neurosci 8, 376.

Fuster-Matanzo A, Llorens-Martin M, de Barreda EG, Avila J \& Hernandez F. (2011). Different susceptibility to neurodegeneration of dorsal and ventral hippocampal dentate gyrus: a study with transgenic mice overexpressing GSK3beta. PLoS One 6, e27262.

Gallagher M \& Chiba AA. (1996). The amygdala and emotion. Curr Opin Neurobiol 6, 221-227. 
Gaviria M, Pliskin N \& Kney A. (2011). Cognitive impairment in patients with advanced heart failure and its implications on decision-making capacity. Congest Heart Fail 17, 175-179.

Giovannini MG, Pazzagli M, Malmberg-Aiello P, Della Corte L, Rakovska AD, Cerbai F, Casamenti F \& Pepeu G. (2005). Inhibition of acetylcholine-induced activation of extracellular regulated protein kinase prevents the encoding of an inhibitory avoidance response in the rat. Neuroscience 136, 15-32.

Goldman-Rakic PS. (1996). The prefrontal landscape: implications of functional architecture for understanding human mentation and the central executive. Philos Trans R Soc Lond B Biol Sci 351, 1445-1453.

Goldsmith SR, Francis GS, Cowley AW, Jr., Levine TB \& Cohn JN. (1983). Increased plasma arginine vasopressin levels in patients with congestive heart failure. J Am Coll Cardiol 1, 1385-1390.

Gottlieb SS, Khatta M, Friedmann E, Einbinder L, Katzen S, Baker B, Marshall J, Minshall S, Robinson S, Fisher ML, Potenza M, Sigler B, Baldwin C \& Thomas SA. (2004). The influence of age, gender, and race on the prevalence of depression in heart failure patients. $J \mathrm{Am}$ Coll Cardiol 43, 1542-1549.

Guzowski JF, Lyford GL, Stevenson GD, Houston FP, McGaugh JL, Worley PF \& Barnes CA. (2000). Inhibition of activity-dependent arc protein expression in the rat hippocampus impairs the maintenance of long-term potentiation and the consolidation of long-term memory. J Neurosci 20, 3993-4001.

Han TH, Lee K, Park JB, Ahn D, Park JH, Kim DY, Stern JE, Lee SY \& Ryu PD. (2010). Reduction in synaptic GABA release contributes to target-selective elevation of PVN neuronal activity in rats with myocardial infarction. Am J Physiol Regul Integr Comp Physiol 299, R129-139.

Han XR, Wen X, Wang YJ, Wang S, Shen M, Zhang ZF, Fan SH, Shan Q, Wang L, Li MQ, Hu B, Sun $\mathrm{CH}, \mathrm{Wu} \mathrm{DM}$, Lu J \& Zheng YL. (2018). Effects of CREB1 gene silencing on cognitive dysfunction by mediating PKA-CREB signaling pathway in mice with vascular dementia. Mol Med 24, 18.

Handley SL \& Mithani S. (1984). Effects of alpha-adrenoceptor agonists and antagonists in a maze-exploration model of 'fear'-motivated behaviour. Naunyn Schmiedebergs Arch Pharmacol 327, 1-5.

Harkness K, Demers C, Heckman GA \& McKelvie RS. (2011). Screening for cognitive deficits using the Montreal cognitive assessment tool in outpatients $>/=65$ years of age with heart failure. Am J Cardiol 107, 1203-1207.

Hasan MT, Althammer F, Silva da Gouveia M, Goyon S, Eliava M, Lefevre A, Kerspern D, Schimmer J, Raftogianni A, Wahis J, Knobloch-Bollmann HS, Tang Y, Liu X, Jain A, Chavant V, Goumon 
Y, Weislogel JM, Hurlemann R, Herpertz SC, Pitzer C, Darbon P, Dogbevia GK, Bertocchi I, Larkum ME, Sprengel R, Bading H, Charlet A \& Grinevich V. (2019). A Fear Memory Engram and Its Plasticity in the Hypothalamic Oxytocin System. Neuron 103, 133-146 e138.

Hay M, Vanderah TW, Samareh-Jahani F, Constantopoulos E, Uprety AR, Barnes CA \& Konhilas J. (2017). Cognitive impairment in heart failure: A protective role for angiotensin-(1-7). Behav Neurosci 131, 99-114.

Hayward LF, Hampton EE, Ferreira LF, Christou DD, Yoo JK, Hernandez ME \& Martin EJ. (2015). Chronic heart failure alters orexin and melanin concentrating hormone but not corticotrophin releasing hormone-related gene expression in the brain of male Lewis rats. Neuropeptides 52, 67-72.

Hjelm C, Dahl A, Brostrom A, Martensson J, Johansson B \& Stromberg A. (2012). The influence of heart failure on longitudinal changes in cognition among individuals 80 years of age and older. J Clin Nurs 21, 994-1003.

Hodsman GP, Kohzuki M, Howes LG, Sumithran E, Tsunoda K \& Johnston Cl. (1988). Neurohumoral responses to chronic myocardial infarction in rats. Circulation 78, 376-381.

Holly KS, Orndorff CO \& Murray TA. (2016). MATSAP: An automated analysis of stretch-attend posture in rodent behavioral experiments. Sci Rep 6, 31286.

Hong YM, Jo DG, Lee JY, Chang JW, Nam JH, Noh JY, Koh JY \& Jung YK. (2003). Down-regulation of ARC contributes to vulnerability of hippocampal neurons to ischemia/hypoxia. FEBS Lett 543, 170-173.

Iadecola C. (2013). The pathobiology of vascular dementia. Neuron 80, 844-866.

Izquierdo LA, Barros DM, Medina JH \& Izquierdo I. (2000). Novelty enhances retrieval of one-trial avoidance learning in rats 1 or 31 days after training unless the hippocampus is inactivated by different receptor antagonists and enzyme inhibitors. Behav Brain Res 117, 215-220.

Janak PH \& Tye KM. (2015). From circuits to behaviour in the amygdala. Nature 517, 284-292.

Jarvik ME \& Kopp R. (1967). An improved one-trial passive avoidance learning situation. Psychol Rep 21, 221-224.

Jefferson AL, Himali JJ, Au R, Seshadri S, Decarli C, O'Donnell CJ, Wolf PA, Manning WJ, Beiser AS \& Benjamin EJ. (2011). Relation of left ventricular ejection fraction to cognitive aging (from the Framingham Heart Study). Am J Cardiol 108, 1346-1351. 
Kabir ZD, Lee AS, Burgdorf CE, Fischer DK, Rajadhyaksha AM, Mok E, Rizzo B, Rice RC, Singh K, Ota KT, Gerhard DM, Schierberl KC, Glass MJ, Duman RS \& Rajadhyaksha AM. (2017). Cacna1c in the Prefrontal Cortex Regulates Depression-Related Behaviors via REDD1. Neuropsychopharmacology 42, 2032-2042.

Kang YM, He RL, Yang LM, Qin DN, Guggilam A, Elks C, Yan N, Guo Z \& Francis J. (2009). Brain tumour necrosis factor-alpha modulates neurotransmitters in hypothalamic paraventricular nucleus in heart failure. Cardiovasc Res 83, 737-746.

Kang YM, Wang Y, Yang LM, Elks C, Cardinale J, Yu XJ, Zhao XF, Zhang J, Zhang LH, Yang ZM \& Francis J. (2010). TNF-alpha in hypothalamic paraventricular nucleus contributes to sympathoexcitation in heart failure by modulating AT1 receptor and neurotransmitters. Tohoku J Exp Med 222, 251-263.

Kang YM, Zhang ZH, Xue B, Weiss RM \& Felder RB. (2008). Inhibition of brain proinflammatory cytokine synthesis reduces hypothalamic excitation in rats with ischemia-induced heart failure. Am J Physiol Heart Circ Physiol 295, H227-236.

Kheirbek MA, Klemenhagen KC, Sahay A \& Hen R. (2012). Neurogenesis and generalization: a new approach to stratify and treat anxiety disorders. Nat Neurosci 15, 1613-1620.

Kleiber AC, Zheng H, Schultz HD, Peuler JD \& Patel KP. (2008). Exercise training normalizes enhanced glutamate-mediated sympathetic activation from the PVN in heart failure. Am J Physiol Regul Integr Comp Physiol 294, R1863-1872.

Knobloch HS, Charlet A, Hoffmann LC, Eliava M, Khrulev S, Cetin AH, Osten P, Schwarz MK, Seeburg PH, Stoop R \& Grinevich V. (2012). Evoked axonal oxytocin release in the central amygdala attenuates fear response. Neuron 73, 553-566.

Kraeuter AK, Guest PC \& Sarnyai Z. (2019). The Elevated Plus Maze Test for Measuring AnxietyLike Behavior in Rodents. Methods Mol Biol 1916, 69-74.

Krishnan V \& Nestler EJ. (2011). Animal models of depression: molecular perspectives. Curr Top Behav Neurosci 7, 121-147.

Lalonde R. (2002). The neurobiological basis of spontaneous alternation. Neurosci Biobehav Rev 26, 91-104.

Lee CS, Gelow JM, Bidwell JT, Mudd JO, Green JK, Jurgens CY \& Woodruff-Pak DS. (2013). Blunted responses to heart failure symptoms in adults with mild cognitive dysfunction. $J$ Cardiovasc Nurs 28, 534-540.

Lehmann H, Treit D \& Parent MB. (2003). Spared anterograde memory for shock-probe fear conditioning after inactivation of the amygdala. Learn Mem 10, 261-269. 
Leto L \& Feola M. (2014). Cognitive impairment in heart failure patients. J Geriatr Cardiol 11, 316328.

Lisboa SF, Stecchini MF, Correa FM, Guimaraes FS \& Resstel LB. (2010). Different role of the ventral medial prefrontal cortex on modulation of innate and associative learned fear. Neuroscience 171, 760-768.

Liu KC, Li JY, Tan HH, Du CX, Xie W, Zhang YM, Ma WL \& Zhang L. (2015). Serotonin(6) receptors in the dorsal hippocampus regulate depressive-like behaviors in unilateral 6hydroxydopamine-lesioned Parkinson's rats. Neuropharmacology 95, 290-298.

Liu MY, Yin CY, Zhu L, Zhu XH, Xu C, Luo CX, Chen H, Zhu DY \& Zhou QG. (2018). Sucrose preference test for measurement of stress-induced anhedonia in mice. Nat Protoc 13, 1686-1698.

Liu W, Ge T, Leng Y, Pan Z, Fan J, Yang W \& Cui R. (2017). The Role of Neural Plasticity in Depression: From Hippocampus to Prefrontal Cortex. Neural Plast 2017, 6871089.

Liu Z, Wang Y, Pan S, Zhang Y, Zhu H, Liu Y, Zhu L \& Zhang J. (2019). Platelets-released insulin-like growth factor 1 is correlated with anxiety in myocardial infarction. Biochem Biophys Res Commun 520, 441-448.

Lossnitzer N, Herzog W, Stork S, Wild B, Muller-Tasch T, Lehmkuhl E, Zugck C, Regitz-Zagrosek V, Pankuweit S, Maisch B, Ertl G, Gelbrich G, Angermann CE \& Competence Network Heart F. (2013). Incidence rates and predictors of major and minor depression in patients with heart failure. Int J Cardiol 167, 502-507.

Lu X, Wang Y, Liu C \& Wang Y. (2017). Depressive disorder and gastrointestinal dysfunction after myocardial infarct are associated with abnormal tryptophan-5-hydroxytryptamine metabolism in rats. PLoS One 12, e0172339.

Lu Z, Yang T, Wang L, Qiu Q, Zhao Y, Wu A, Li T, Cheng W, Wang B, Li Y, Yang J \& Zhao M. (2020). Comparison of different protocols of Morris water maze in cognitive impairment with heart failure. Brain Behav 10, e01519.

Mancia G. (1990). Sympathetic activation in congestive heart failure. Eur Heart J 11 Suppl A, 311.

Martin N, Bossenmeyer-Pourie C, Koziel V, Jazi R, Audonnet S, Vert P, Gueant JL, Daval JL \& Pourie G. (2012). Non-injurious neonatal hypoxia confers resistance to brain senescence in aged male rats. PLoS One 7, e48828. 
Mikics E, Barsy B, Barsvari B \& Haller J. (2005). Behavioral specificity of non-genomic glucocorticoid effects in rats: effects on risk assessment in the elevated plus-maze and the open-field. Horm Behav 48, 152-162.

Montgomery KC. (1955). The relation between fear induced by novel stimulation and exploratory behavior. J Comp Physiol Psychol 48, 254-260.

Moser MB \& Moser El. (1998). Functional differentiation in the hippocampus. Hippocampus 8, 608-619.

Najjar E, Stalhberg M, Hage C, Ottenblad E, Manouras A, Haugen Lofman I \& Lund LH. (2018a). Haemodynamic effects of levosimendan in advanced but stable chronic heart failure. ESC Heart Fail 5, 302-308.

Najjar F, Ahmad M, Lagace D \& Leenen FHH. (2018b). Sex differences in depression-like behavior and neuroinflammation in rats post-MI: role of estrogens. Am J Physiol Heart Circ Physiol 315, H1159-H1173.

Nobre MJ. (2013). Changes on auditory physiology in response to the inactivation of amygdala nuclei in high anxiety rats expressing learned fear. Physiol Behav 118, 80-87.

O'Donnell M, Teo K, Gao P, Anderson C, Sleight P, Dans A, Marzona I, Bosch J, Probstfield J \& Yusuf S. (2012). Cognitive impairment and risk of cardiovascular events and mortality. Eur Heart J 33, 1777-1786.

Ong WY, Stohler CS \& Herr DR. (2019). Role of the Prefrontal Cortex in Pain Processing. Mol Neurobiol 56, 1137-1166.

Packer M. (1988). Neurohormonal interactions and adaptations in congestive heart failure. Circulation 77, 721-730.

Parent MB, Tomaz C \& McGaugh JL. (1992). Increased training in an aversively motivated task attenuates the memory-impairing effects of posttraining $\mathrm{N}$-methyl-D-aspartate-induced amygdala lesions. Behav Neurosci 106, 789-797.

Park S, Park JM, Kim S, Kim JA, Shepherd JD, Smith-Hicks CL, Chowdhury S, Kaufmann W, Kuhl D, Ryazanov AG, Huganir RL, Linden DJ \& Worley PF. (2008). Elongation factor 2 and fragile $X$ mental retardation protein control the dynamic translation of Arc/Arg3.1 essential for mGluR-LTD. Neuron 59, 70-83.

Patel KP. (2000). Role of paraventricular nucleus in mediating sympathetic outflow in heart failure. Heart Fail Rev 5, 73-86. 
Paxinos G \& Watson C. (2006). The rat brain in stereotaxic coordinates: hard cover edition. Elsevier.

Pellow S, Chopin P, File SE \& Briley M. (1985). Validation of open:closed arm entries in an elevated plus-maze as a measure of anxiety in the rat. J Neurosci Methods 14, 149-167.

Pi G, Gao D, Wu D, Wang Y, Lei H, Zeng W, Gao Y, Yu H, Xiong R, Jiang T, Li S, Wang X, Guo J, Zhang S, Yin T, He T, Ke D, Li R, Li H, Liu G, Yang X, Luo MH, Zhang X, Yang Y \& Wang JZ. (2020). Posterior basolateral amygdala to ventral hippocampal CA1 drives approach behaviour to exert an anxiolytic effect. Nat Commun 11, 183.

Plath N, Ohana O, Dammermann B, Errington ML, Schmitz D, Gross C, Mao X, Engelsberg A, Mahlke C, Welzl H, Kobalz U, Stawrakakis A, Fernandez E, Waltereit R, Bick-Sander A, Therstappen E, Cooke SF, Blanquet V, Wurst W, Salmen B, Bosl MR, Lipp HP, Grant SG, Bliss TV, Wolfer DP \& Kuhl D. (2006). Arc/Arg3.1 is essential for the consolidation of synaptic plasticity and memories. Neuron $\mathbf{5 2}, 437-444$.

Potapenko ES, Biancardi VC, Florschutz RM, Ryu PD \& Stern JE. (2011). Inhibitory-excitatory synaptic balance is shifted toward increased excitation in magnocellular neurosecretory cells of heart failure rats. J Neurophysiol 106, 1545-1557.

Potapenko ES, Biancardi VC, Zhou Y \& Stern JE. (2012). Altered astrocyte glutamate transporter regulation of hypothalamic neurosecretory neurons in heart failure rats. Am J Physiol Regul Integr Comp Physiol 303, R291-300.

Potapenko ES, Biancardi VC, Zhou Y \& Stern JE. (2013). Astrocytes modulate a postsynaptic NMDA-GABAA-receptor crosstalk in hypothalamic neurosecretory neurons. J Neurosci 33, 631-640.

Prager EM, Bergstrom HC, Wynn GH \& Braga MF. (2016). The basolateral amygdala gammaaminobutyric acidergic system in health and disease. J Neurosci Res 94, 548-567.

Pressler SJ, Kim J, Riley P, Ronis DL \& Gradus-Pizlo I. (2010a). Memory dysfunction, psychomotor slowing, and decreased executive function predict mortality in patients with heart failure and low ejection fraction. J Card Fail 16, 750-760.

Pressler SJ, Subramanian U, Kareken D, Perkins SM, Gradus-Pizlo I, Sauve MJ, Ding Y, Kim J, Sloan R, Jaynes H \& Shaw RM. (2010b). Cognitive deficits in chronic heart failure. Nurs Res 59, 127-139.

Price JL \& Drevets WC. (2010). Neurocircuitry of mood disorders. Neuropsychopharmacology 35, 192-216. 
Prickaerts J, Raaijmakers W \& Blokland A. (1996). Effects of myocardial infarction and captopril therapy on anxiety-related behaviors in the rat. Physiol Behav 60, 43-50.

Pullicino PM \& Hart J. (2001). Cognitive impairment in congestive heart failure?: Embolism vs hypoperfusion. Neurology 57, 1945-1946.

Quevedo J, Vianna M, Zanatta MS, Roesler R, Izquierdo I, Jerusalinsky D \& Quillfeldt JA. (1997). Involvement of mechanisms dependent on NMDA receptors, nitric oxide and protein kinase $A$ in the hippocampus but not in the caudate nucleus in memory. Behav Pharmacol 8, 713-717.

Quiroz C, Martinez I, Quirarte GL, Morales T, Diaz-Cintra S \& Prado-Alcala RA. (2003). Enhanced inhibitory avoidance learning prevents the memory-impairing effects of post-training hippocampal inactivation. Exp Brain Res 153, 400-402.

Rana I, Stebbing M, Kompa A, Kelly DJ, Krum H \& Badoer E. (2010). Microglia activation in the hypothalamic PVN following myocardial infarction. Brain Res 1326, 96-104.

Richman CL, Dember, W.N. \& Kim, P. (1986). Spontaneous alternation behavior in animals: A review. Current Psychology 5, 358-391.

Roozendaal B, McEwen BS \& Chattarji S. (2009). Stress, memory and the amygdala. Nat Rev Neurosci 10, 423-433.

Roozendaal B \& McGaugh JL. (1997). Basolateral amygdala lesions block the memory-enhancing effect of glucocorticoid administration in the dorsal hippocampus of rats. Eur J Neurosci 9, 76-83.

Roy B, Woo MA, Wang DJJ, Fonarow GC, Harper RM \& Kumar R. (2017). Reduced regional cerebral blood flow in patients with heart failure. Eur J Heart Fail 19, 1294-1302.

Rutledge T, Reis VA, Linke SE, Greenberg BH \& Mills PJ. (2006). Depression in heart failure a metaanalytic review of prevalence, intervention effects, and associations with clinical outcomes. J Am Coll Cardiol 48, 1527-1537.

Sadamoto H, Kitahashi T, Fujito Y \& Ito E. (2010). Learning-Dependent Gene Expression of CREB1 Isoforms in the Molluscan Brain. Front Behav Neurosci 4, 25.

Sahay A \& Hen R. (2007). Adult hippocampal neurogenesis in depression. Nat Neurosci 10, 11101115.

Sakaguchi Y \& Sakurai Y. (2020). Left-right functional difference of the rat dorsal hippocampus for short-term memory and long-term memory. Behav Brain Res 382, 112478. 
Salazar AP, Quagliotto E, Alves J, Oliveira FA, Saur L, Xavier LL, Pagnussat AS \& Rasia-Filho A. (2014). Effect of prior exercise training and myocardial infarction-induced heart failure on the neuronal and glial densities and the GFAP-immunoreactivity in the posterodorsal medial amygdala of rats. Histol Histopathol 29, 1423-1435.

Shah AA \& Treit D. (2003). Excitotoxic lesions of the medial prefrontal cortex attenuate fear responses in the elevated-plus maze, social interaction and shock probe burying tests. Brain Res 969, 183-194.

Shapiro ML, Kennedy PJ \& Ferbinteanu J. (2006). Representing episodes in the mammalian brain. Curr Opin Neurobiol 16, 701-709.

Simonyi A, Zhang JP \& Sun GY. (1999). Changes in mRNA levels for group I metabotropic glutamate receptors following in utero hypoxia-ischemia. Brain Res Dev Brain Res 112, 31-37.

Smith JR, Hayman GT, Wang SJ, Laulederkind SJF, Hoffman MJ, Kaldunski ML, Tutaj M, Thota J, Nalabolu HS, Ellanki SLR, Tutaj MA, De Pons JL, Kwitek AE, Dwinell MR \& Shimoyama ME. (2020). The Year of the Rat: The Rat Genome Database at 20: a multi-species knowledgebase and analysis platform. Nucleic Acids Res 48, D731-D742.

Sorregotti T, Cipriano AC, Cruz FC, Mascarenhas DC, Rodgers RJ \& Nunes-de-Souza RL. (2018). Amygdaloid involvement in the defensive behavior of mice exposed to the open elevated plus-maze. Behav Brain Res 338, 159-165.

Squire LR \& Cave CB. (1991). The hippocampus, memory, and space. Hippocampus 1, 269-271.

Stern JE \& Potapenko ES. (2013). Enhanced NMDA receptor-mediated intracellular calcium signaling in magnocellular neurosecretory neurons in heart failure rats. Am J Physiol Regul Integr Comp Physiol 305, R414-422.

Stouffer EM, Warninger EE \& Michener PN. (2015). A high-fat diet impairs learning that is dependent on the dorsal hippocampus but spares other forms of learning. Hippocampus 25, 1567-1576.

Strauss CV, Vicente MA \& Zangrossi H, Jr. (2013). Activation of 5-HT1A receptors in the rat basolateral amygdala induces both anxiolytic and antipanic-like effects. Behav Brain Res 246, 103-110.

Strekalova T, Spanagel R, Bartsch D, Henn FA \& Gass P. (2004). Stress-induced anhedonia in mice is associated with deficits in forced swimming and exploration. Neuropsychopharmacology 29, 2007-2017. 
Su B, Wang XT, Sun YH, Long MY, Zheng J, Wu WH \& Li L. (2020). Ischemia/hypoxia inhibits cardiomyocyte autophagy and promotes apoptosis via the Egr-1/Bim/Beclin-1 pathway. $J$ Geriatr Cardiol 17, 284-293.

Teffer K \& Semendeferi K. (2012). Human prefrontal cortex: evolution, development, and pathology. Prog Brain Res 195, 191-218.

Thompson CL, Pathak SD, Jeromin A, Ng LL, MacPherson CR, Mortrud MT, Cusick A, Riley ZL, Sunkin SM, Bernard A, Puchalski RB, Gage FH, Jones AR, Bajic VB, Hawrylycz MJ \& Lein ES. (2008). Genomic anatomy of the hippocampus. Neuron 60, 1010-1021.

Toledo C, Lucero C, Andrade DC, Diaz HS, Schwarz KG, Pereyra KV, Arce-Alvarez A, Lopez NA, Martinez M, Inestrosa NC \& Del Rio R. (2019). Cognitive impairment in heart failure is associated with altered Wnt signaling in the hippocampus. Aging (Albany NY) 11, 59245942.

Torkaman-Boutorabi A, Sheidadoust H, Hashemi-Hezaveh SM \& Zarrindast MR. (2015). Influence of morphine on medial prefrontal cortex alpha2 adrenergic system in passive avoidance learning in rats. Pharmacol Biochem Behav 133, 92-98.

Torres-Garcia ME, Medina AC, Quirarte GL \& Prado-Alcala RA. (2017). Differential Effects of Inactivation of Discrete Regions of Medial Prefrontal Cortex on Memory Consolidation of Moderate and Intense Inhibitory Avoidance Training. Front Pharmacol 8, 842.

Tournier BB, Tsartsalis S, Rigaud D, Fossey C, Cailly T, Fabis F, Pham T, Gregoire MC, Kovari E, Moulin-Sallanon M, Savioz A \& Millet P. (2019). TSPO and amyloid deposits in sub-regions of the hippocampus in the 3xTgAD mouse model of Alzheimer's disease. Neurobiol Dis 121, 95-105.

Tye KM, Prakash R, Kim SY, Fenno LE, Grosenick L, Zarabi H, Thompson KR, Gradinaru V, Ramakrishnan C \& Deisseroth K. (2011). Amygdala circuitry mediating reversible and bidirectional control of anxiety. Nature 471, 358-362.

Vazdarjanova A. (2002). Passive (Inhibitory) Avoidance, Fear Learning Macmillian Reference USA, FArmington Hill, MI.

Velazquez R, Shaw DM, Caccamo A \& Oddo S. (2016). Pim1 inhibition as a novel therapeutic strategy for Alzheimer's disease. Mol Neurodegener 11, 52.

Ventura-Silva AP, Melo A, Ferreira AC, Carvalho MM, Campos FL, Sousa N \& Pego JM. (2013). Excitotoxic lesions in the central nucleus of the amygdala attenuate stress-induced anxiety behavior. Front Behav Neurosci 7, 32. 
Wang H, Ferguson GD, Pineda VV, Cundiff PE \& Storm DR. (2004). Overexpression of type-1 adenylyl cyclase in mouse forebrain enhances recognition memory and LTP. Nat Neurosci 7, 635-642.

Wang HW, Ahmad M, Jadayel R, Najjar F, Lagace D \& Leenen FHH. (2019). Inhibition of inflammation by minocycline improves heart failure and depression-like behaviour in rats after myocardial infarction. PLoS One 14, e0217437.

Waung MW, Pfeiffer BE, Nosyreva ED, Ronesi JA \& Huber KM. (2008). Rapid translation of Arc/Arg3.1 selectively mediates mGluR-dependent LTD through persistent increases in AMPAR endocytosis rate. Neuron 59, 84-97.

Wilkerson JR, Albanesi JP \& Huber KM. (2018). Roles for Arc in metabotropic glutamate receptordependent LTD and synapse elimination: Implications in health and disease. Semin Cell Dev Biol 77, 51-62.

Willner P, Towell A, Sampson D, Sophokleous S \& Muscat R. (1987). Reduction of sucrose preference by chronic unpredictable mild stress, and its restoration by a tricyclic antidepressant. Psychopharmacology (Berl) 93, 358-364.

Woloszynowska-Fraser MU, Wulff P \& Riedel G. (2017). Parvalbumin-containing GABA cells and schizophrenia: experimental model based on targeted gene delivery through adenoassociated viruses. Behav Pharmacol 28, 630-641.

Wong ST, Athos J, Figueroa XA, Pineda VV, Schaefer ML, Chavkin CC, Muglia LJ \& Storm DR. (1999). Calcium-stimulated adenylyl cyclase activity is critical for hippocampusdependent long-term memory and late phase LTP. Neuron 23, 787-798.

Woo MA, Macey PM, Fonarow GC, Hamilton MA \& Harper RM. (2003). Regional brain gray matter loss in heart failure. J Appl Physiol (1985) 95, 677-684.

Woo MA, Macey PM, Keens PT, Kumar R, Fonarow GC, Hamilton MA \& Harper RM. (2005). Functional abnormalities in brain areas that mediate autonomic nervous system control in advanced heart failure. J Card Fail 11, 437-446.

Woo MA, Palomares JA, Macey PM, Fonarow GC, Harper RM \& Kumar R. (2015). Global and regional brain mean diffusivity changes in patients with heart failure. J Neurosci Res 93, 678-685.

Xu B \& Li H. (2015). Brain mechanisms of sympathetic activation in heart failure: Roles of the reninangiotensin system, nitric oxide and proinflammatory cytokines (Review). Mol Med Rep 12, 7823-7829. 
Yin F, Guo H, Cui J, Shi Y, Su R, Xie Q, Chang J, Wang Y \& Lai J. (2019). The basolateral amygdala regulation of complex cognitive behaviours in the five-choice serial reaction time task. Psychopharmacology (Berl) 236, 3135-3146.

Yu Y, Wei SG, Weiss RM \& Felder RB. (2018). Angiotensin II Type 1a Receptors in the Subfornical Organ Modulate Neuroinflammation in the Hypothalamic Paraventricular Nucleus in Heart Failure Rats. Neuroscience 381, 46-58.

Zeng Q, Huang Z, Zhang J, Liu R, Li X, Zeng J \& Xiao H. (2019). 3'-Daidzein Sulfonate Sodium Protects Against Chronic Cerebral Hypoperfusion-Mediated Cognitive Impairment and Hippocampal Damage via Activity-Regulated Cytoskeleton-Associated Protein Upregulation. Front Neurosci 13, 104.

Zhang K, Li YF \& Patel KP. (2002). Reduced endogenous GABA-mediated inhibition in the PVN on renal nerve discharge in rats with heart failure. Am J Physiol Regul Integr Comp Physiol 282, R1006-1015.

Zhao L, Jiao Q, Chen X, Yang P, Zhao B, Zheng P \& Liu Y. (2012). mGluR5 is involved in proliferation of rat neural progenitor cells exposed to hypoxia with activation of mitogen-activated protein kinase signaling pathway. J Neurosci Res 90, 447-460.

Zheng H, Liu X, Li Y, Sharma NM \& Patel KP. (2011). Gene transfer of neuronal nitric oxide synthase to the paraventricular nucleus reduces the enhanced glutamatergic tone in rats with chronic heart failure. Hypertension 58, 966-973.

Zuccala G, Onder G, Pedone C, Carosella L, Pahor M, Bernabei R, Cocchi A \& Group G-OS. (2001). Hypotension and cognitive impairment: Selective association in patients with heart failure. Neurology 57, 1986-1992.

Zucker IH, Schultz HD, Li YF, Wang Y, Wang W \& Patel KP. (2004). The origin of sympathetic outflow in heart failure: the roles of angiotensin II and nitric oxide. Prog Biophys Mol Biol 84, 217-232. 


\section{Figure 1}

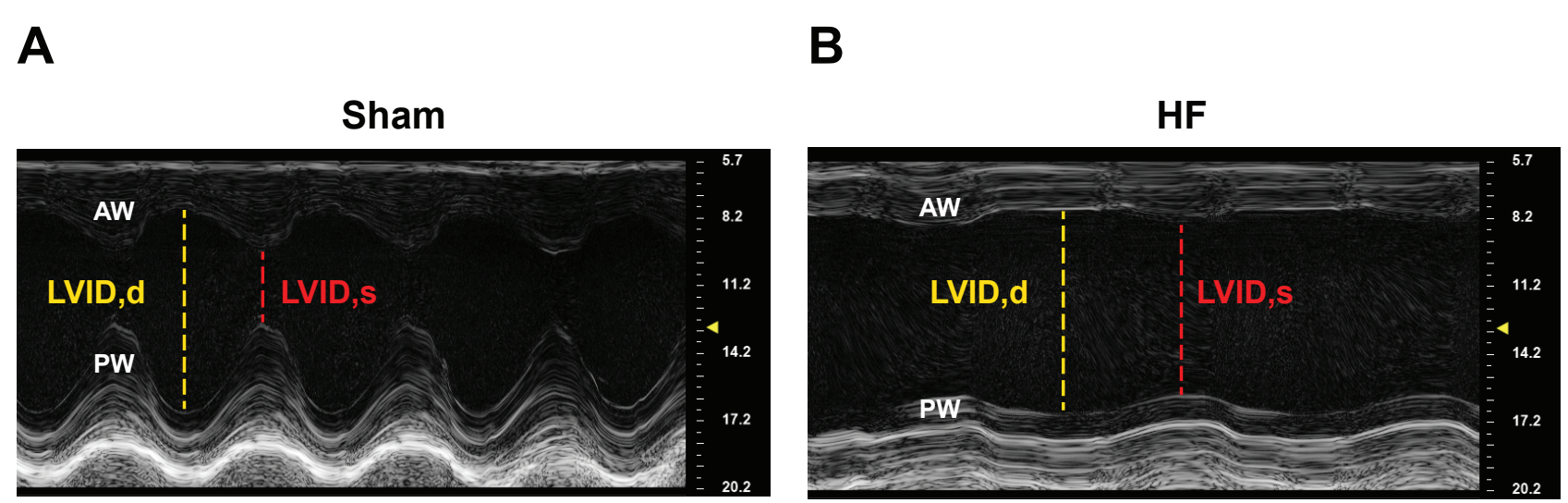




\section{Figure 2}

A

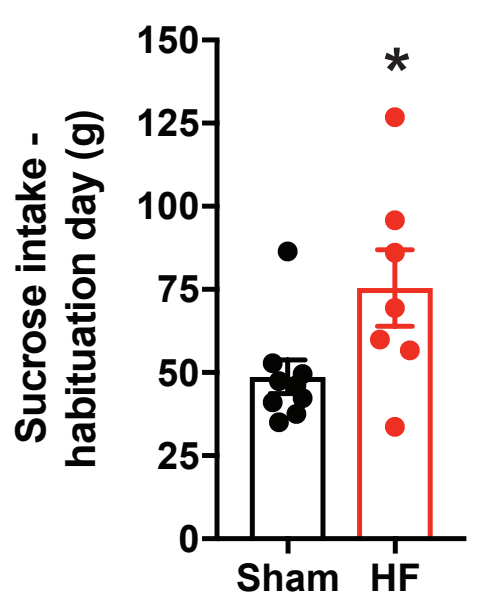

C

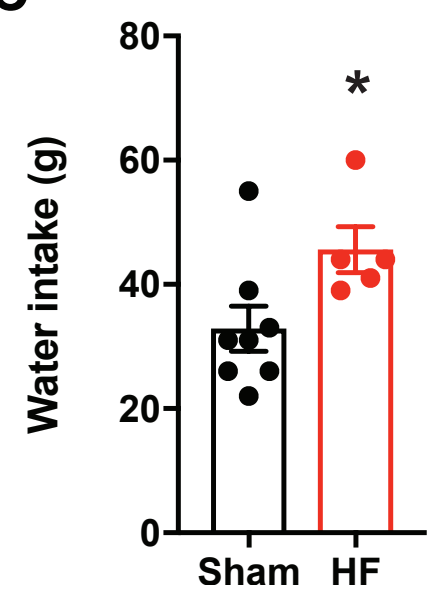

B

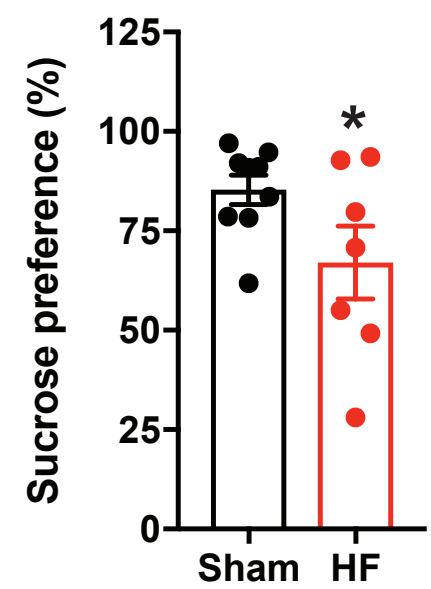

D

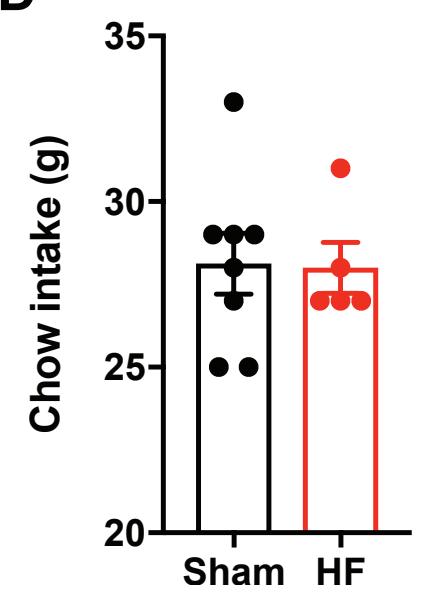

E

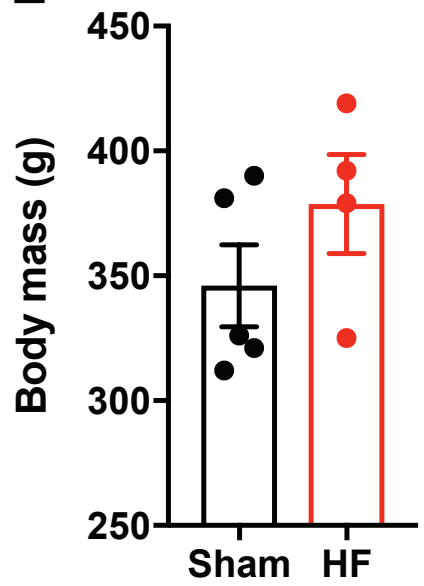


Figure 3
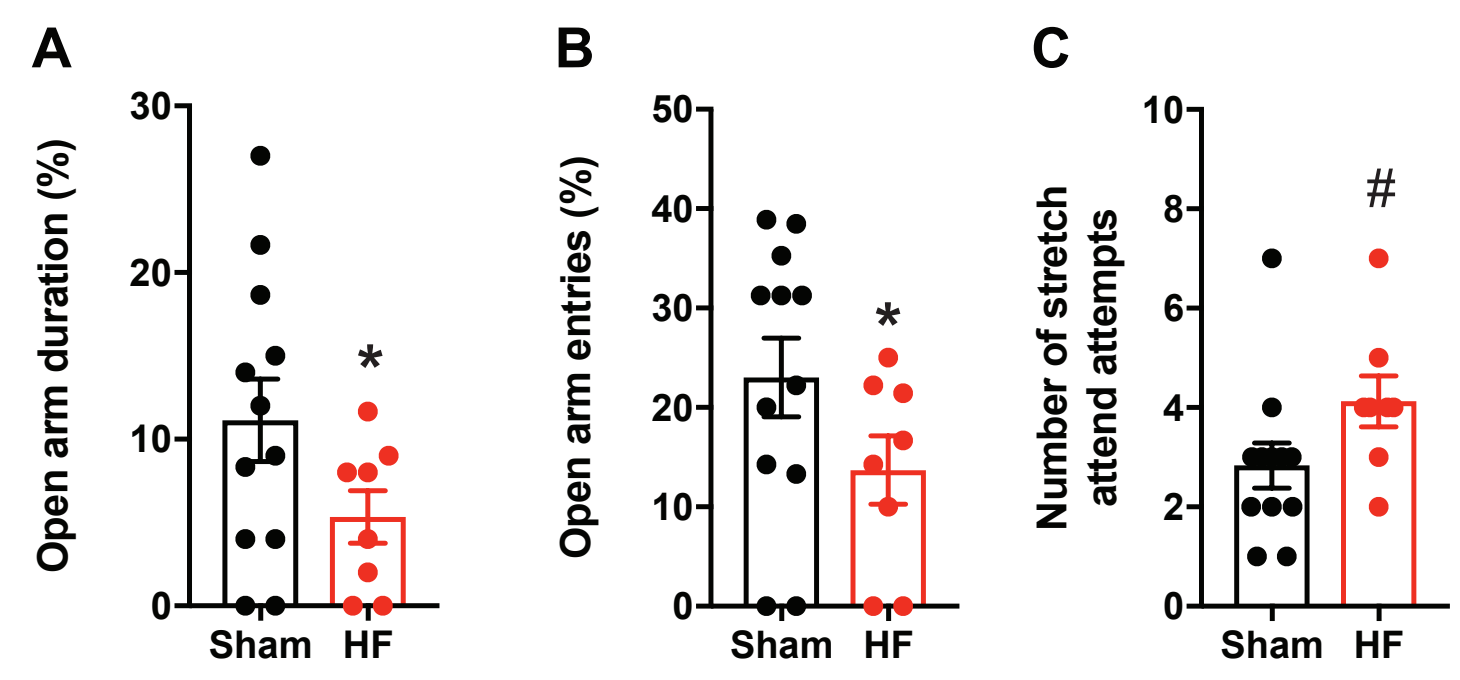
Figure 4

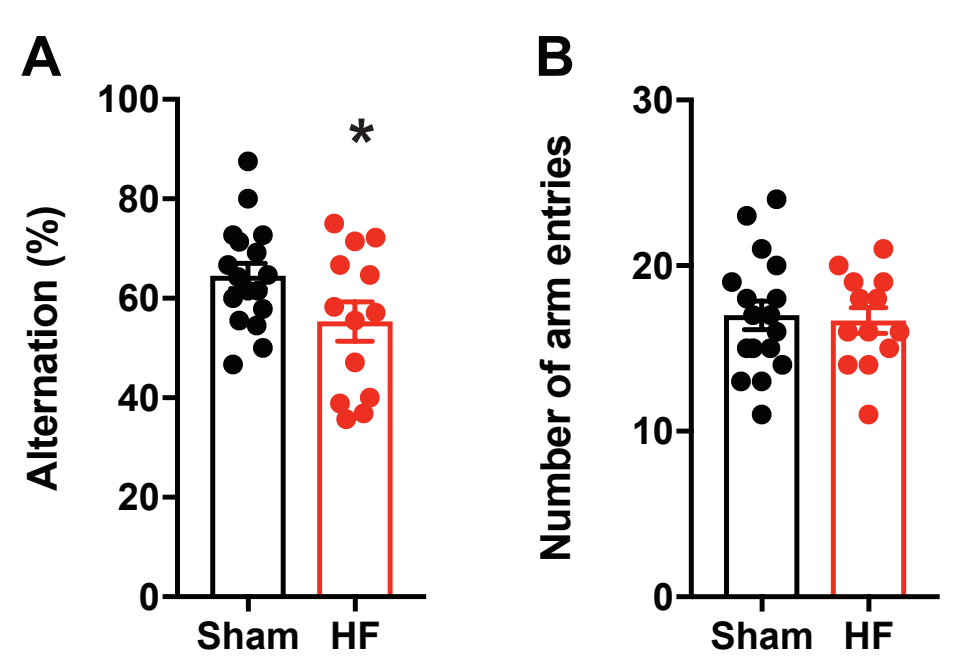




\section{Figure 5}

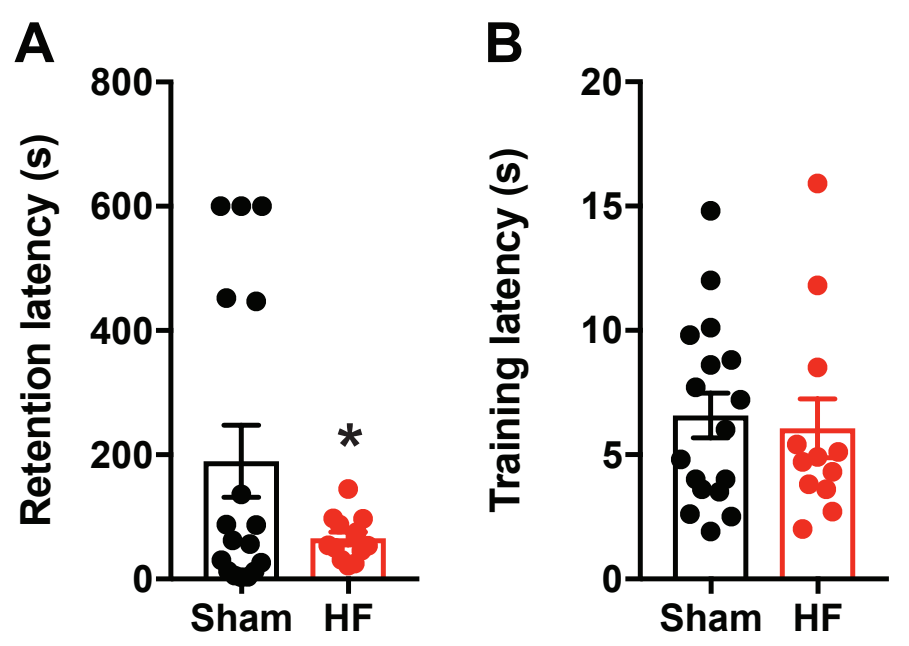


Figure 6

A

PFC PVN DH CeA BLA VH
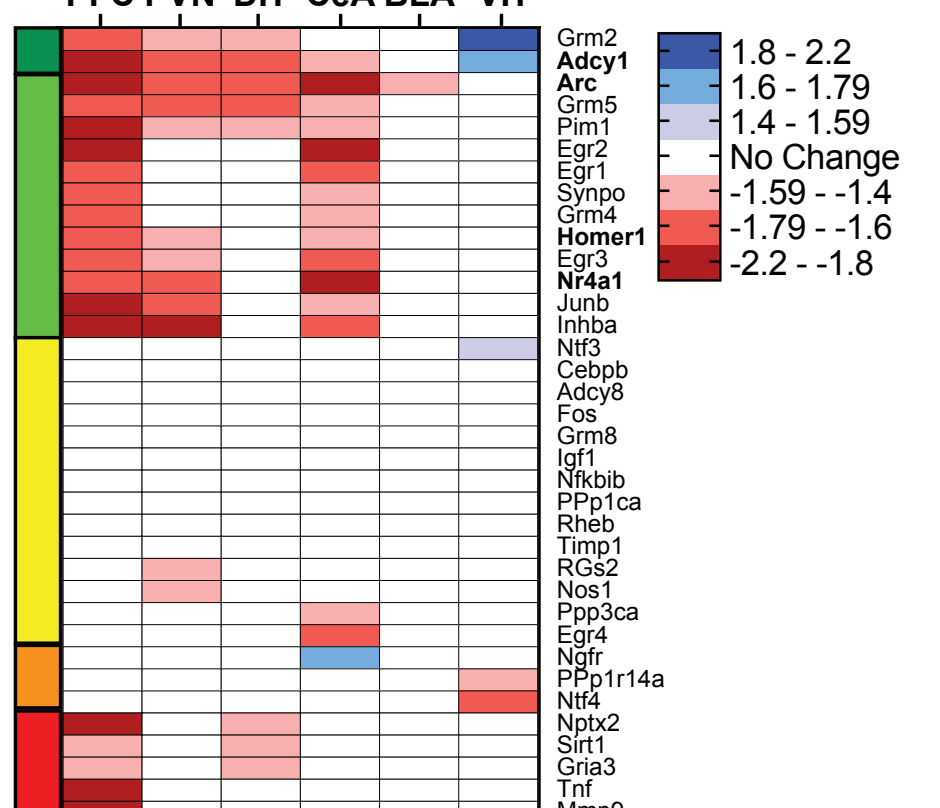

\begin{tabular}{ll|l|l|l|l|l|}
\hline & & & \\
\hline
\end{tabular} \begin{tabular}{ll|l|l|l}
\hline & & & & \\
\hline & & & & \\
$K$
\end{tabular}

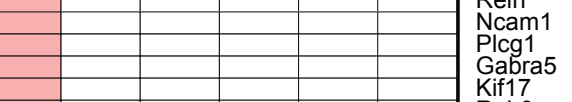

$+$
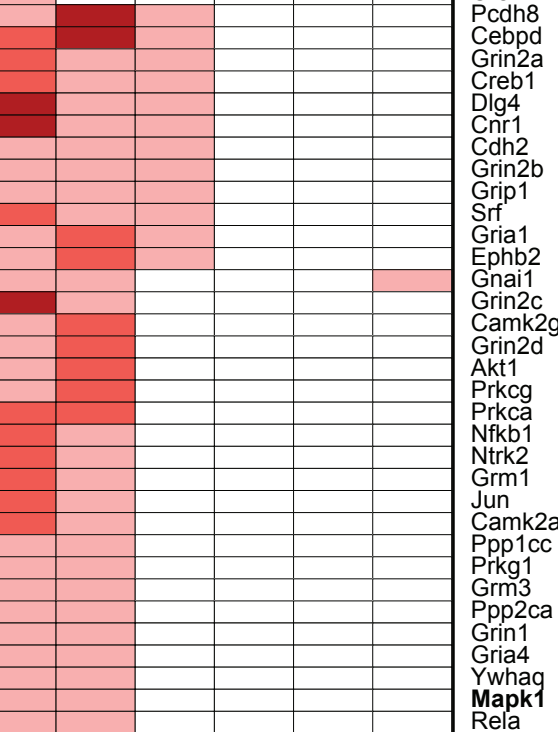

B

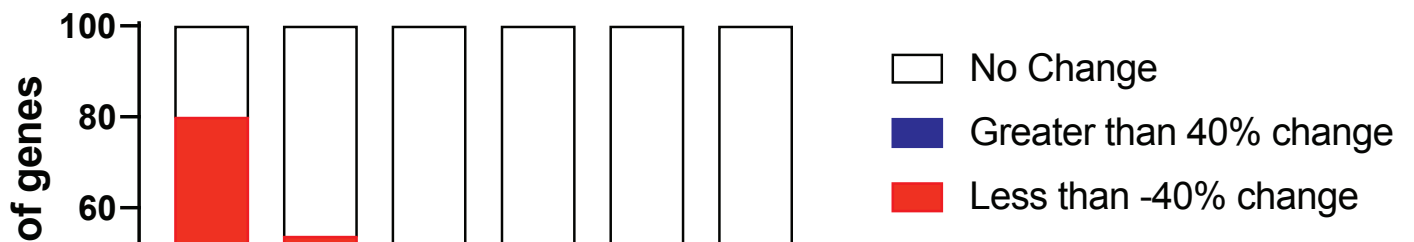

C1

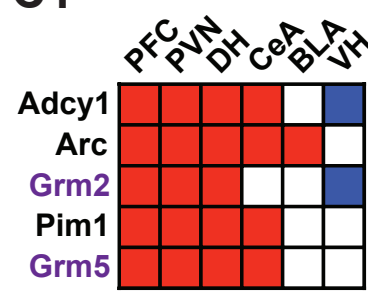

C2

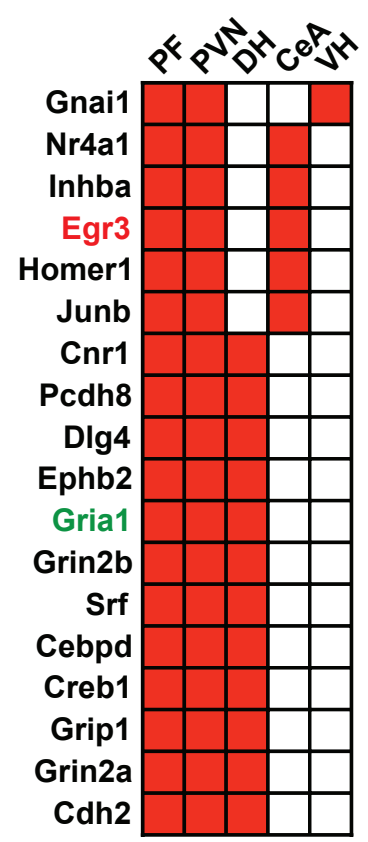

C3

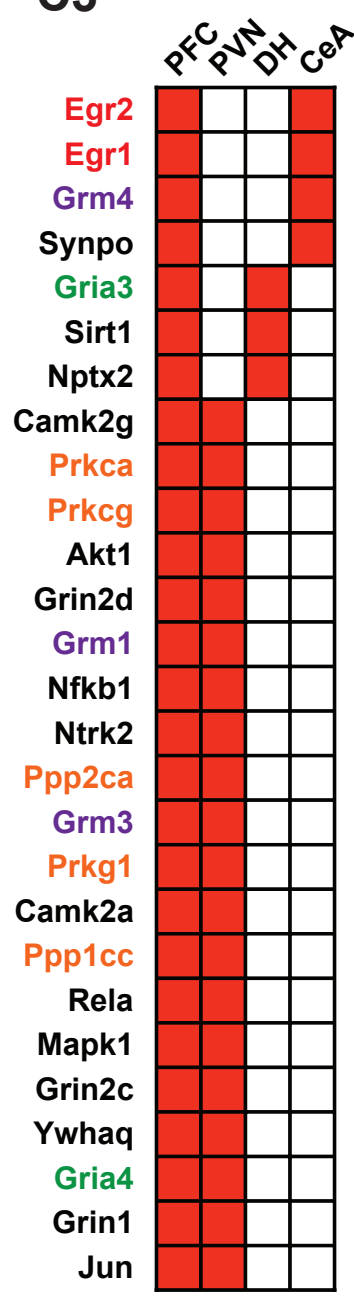

C4

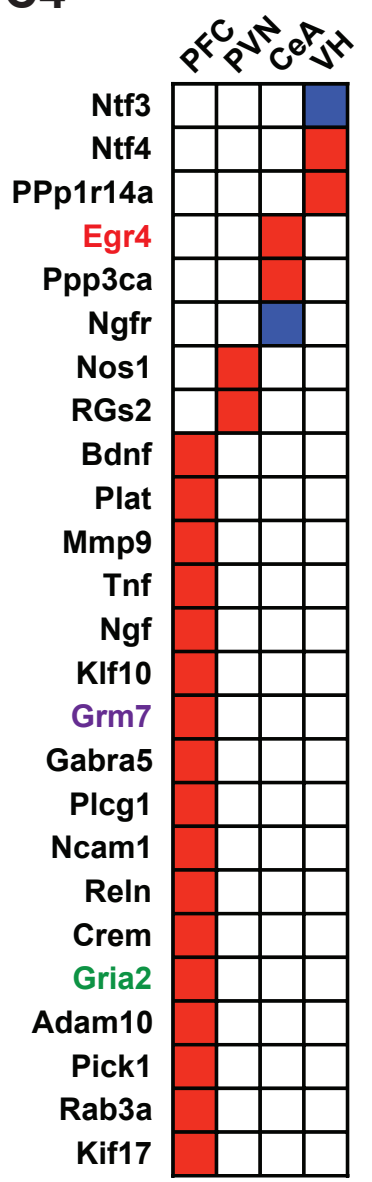




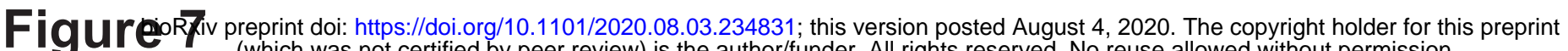
(which was not certified by peer review) is the author/funder. All rights reserved. No reuse allowed without permission.

A

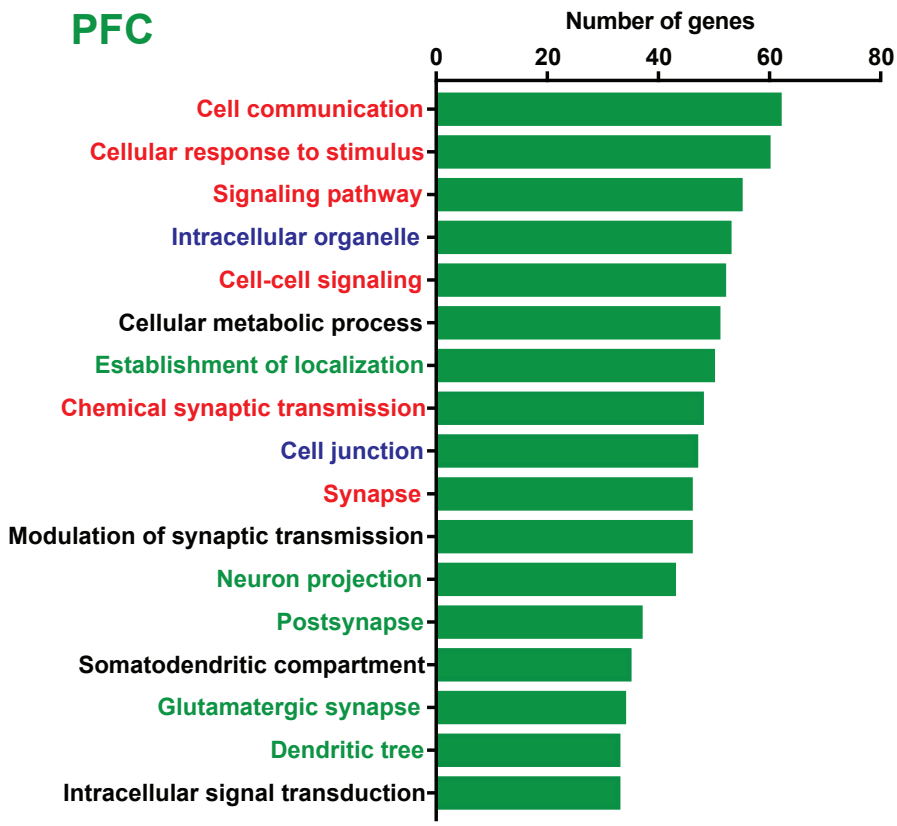

C

DH

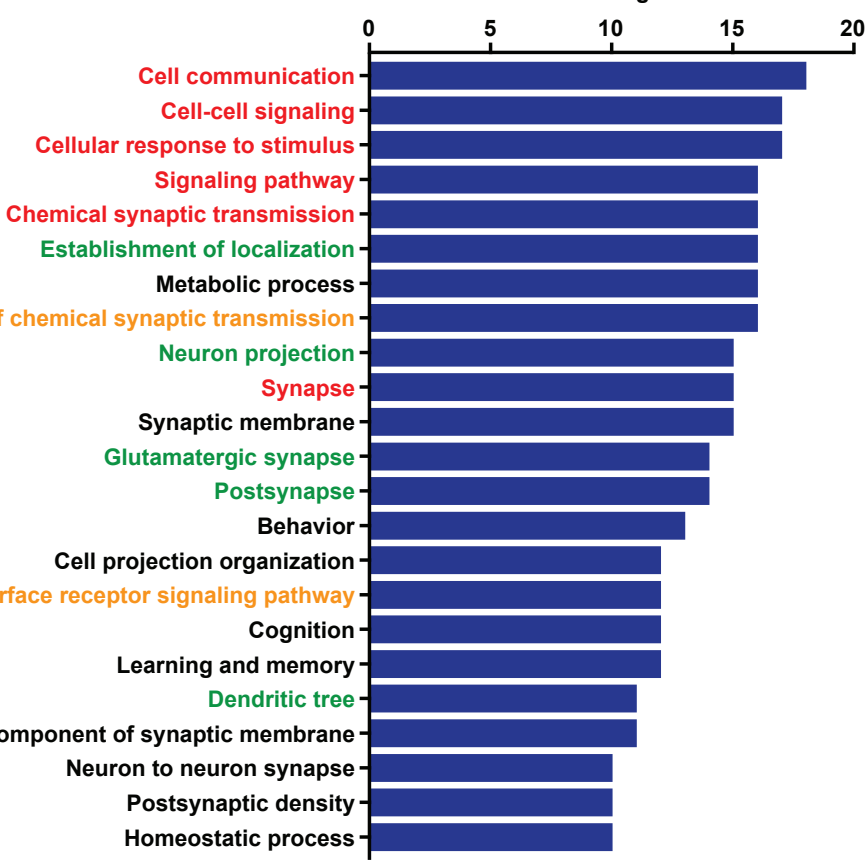

$\mathbf{E}$

\section{CeA}

$$
\begin{array}{r}
\text { Cellular response to stimulus } \\
\text { Intracellular organelle } \\
\text { Cell communication } \\
\text { Signaling pathway } \\
\text { Cell-cell signaling }
\end{array}
$$

Chemical synaptic transmission

Modulation of chemica synaptic transmission

Cell junction

Synapse

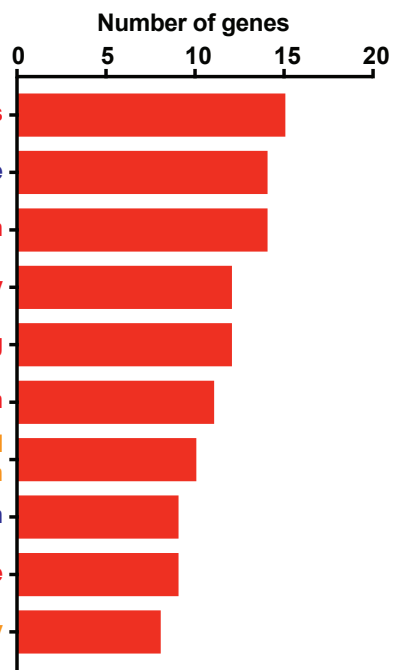

B

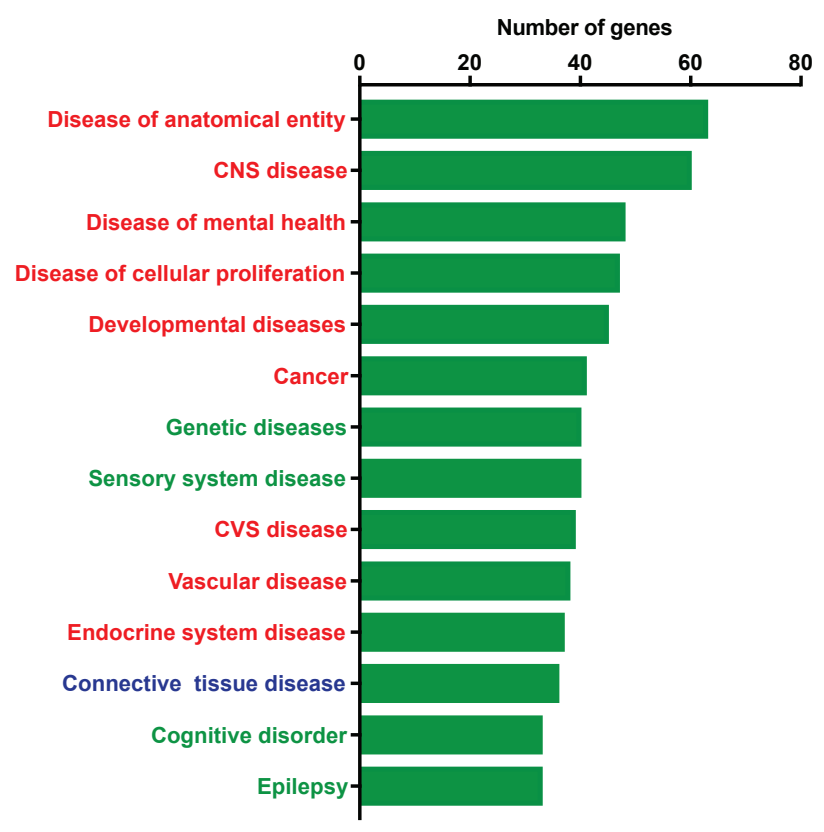

D

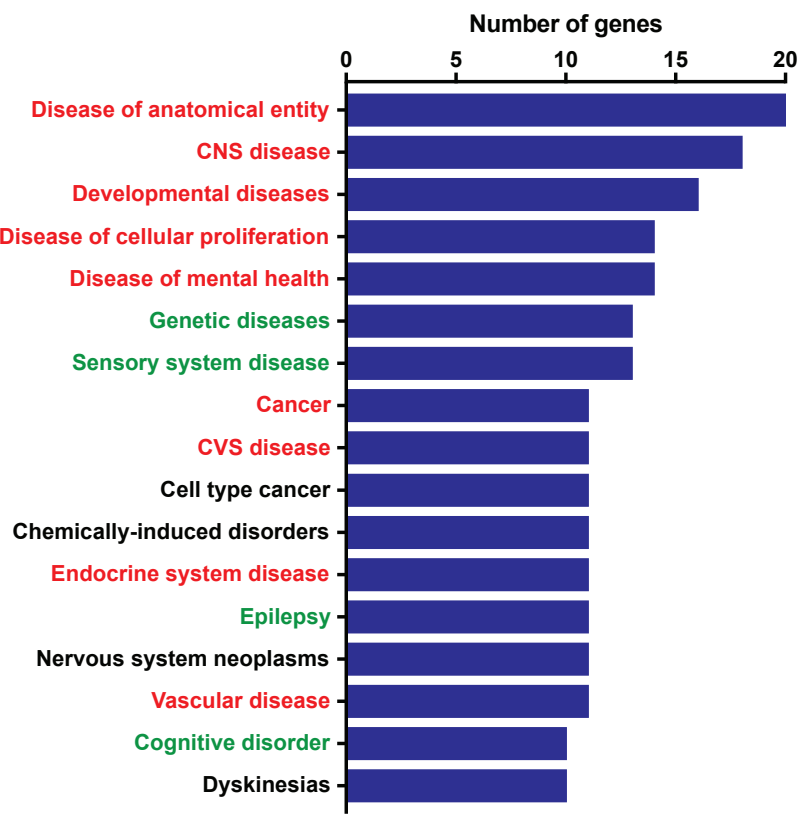

F

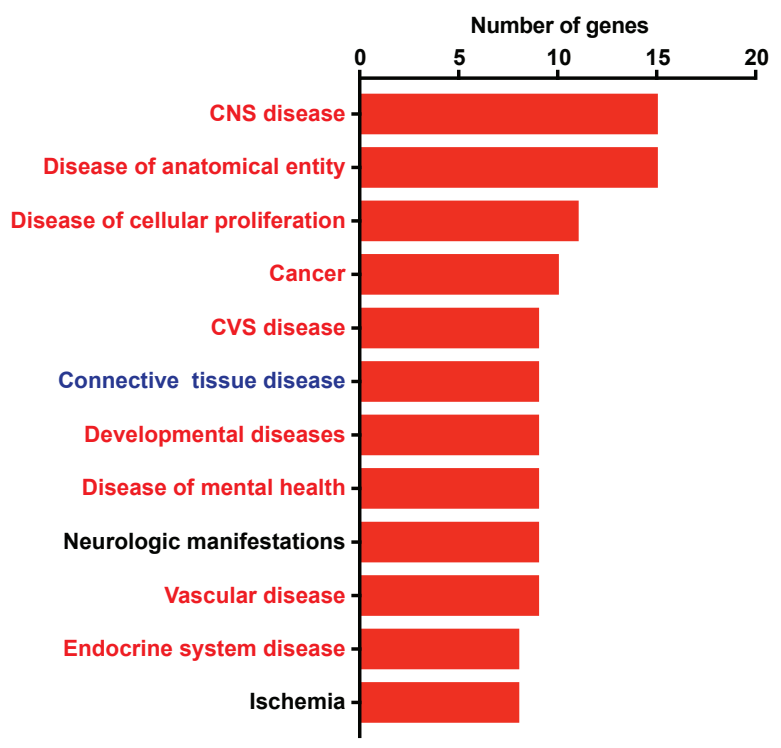



Fig Girfeiv Beprint doi: https://doi.org/10.1101/2020.08.03.234831; this version posted August 4, 2020. The copyright holder for this preprint

A

B

Fold Change

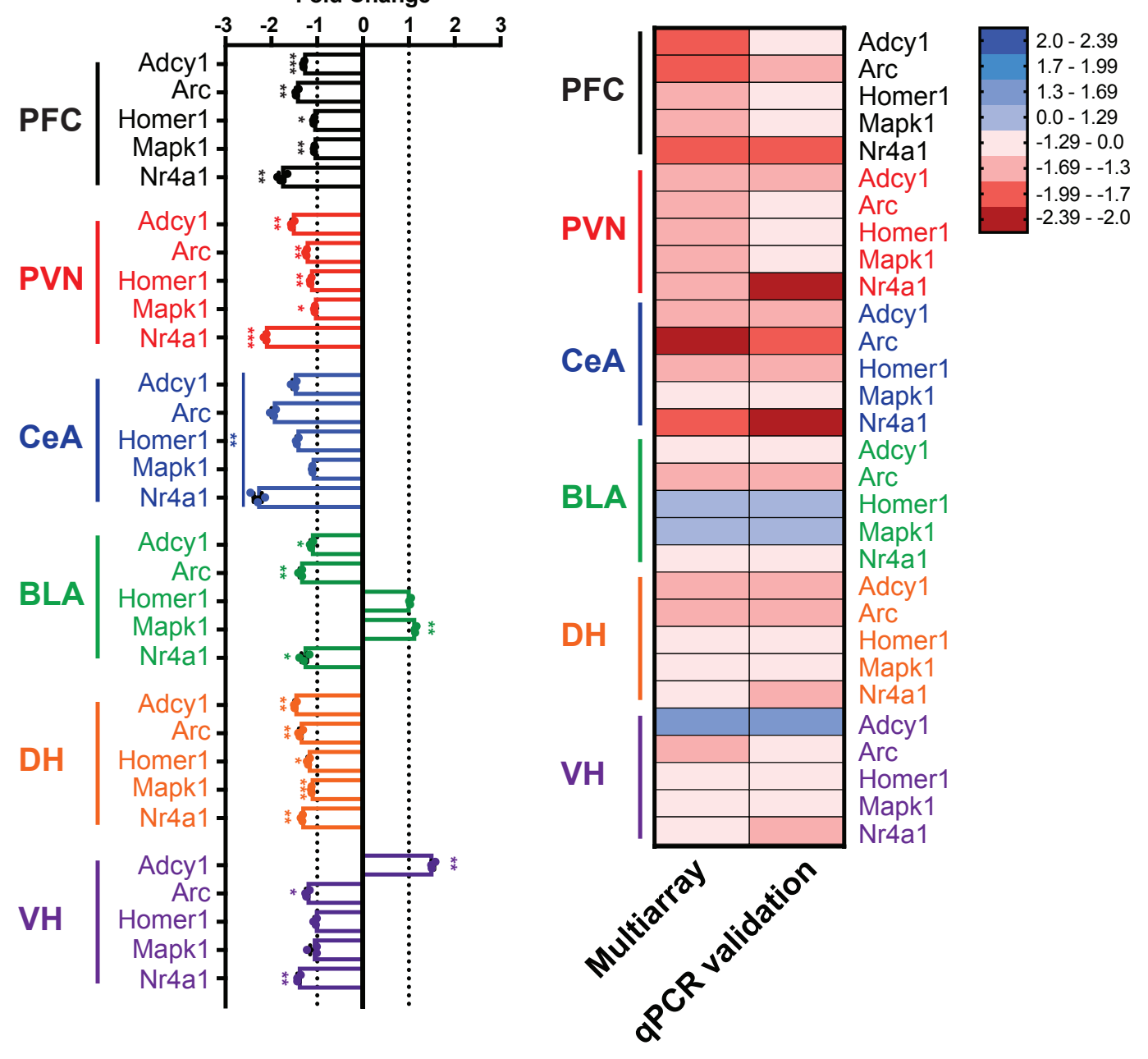


A

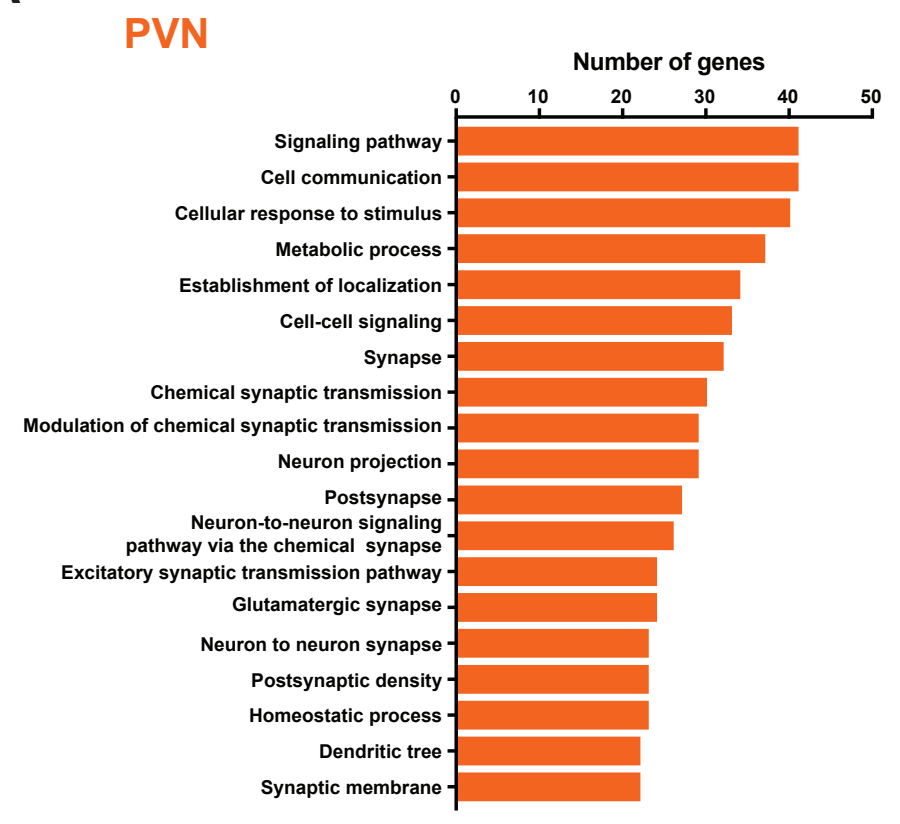

C

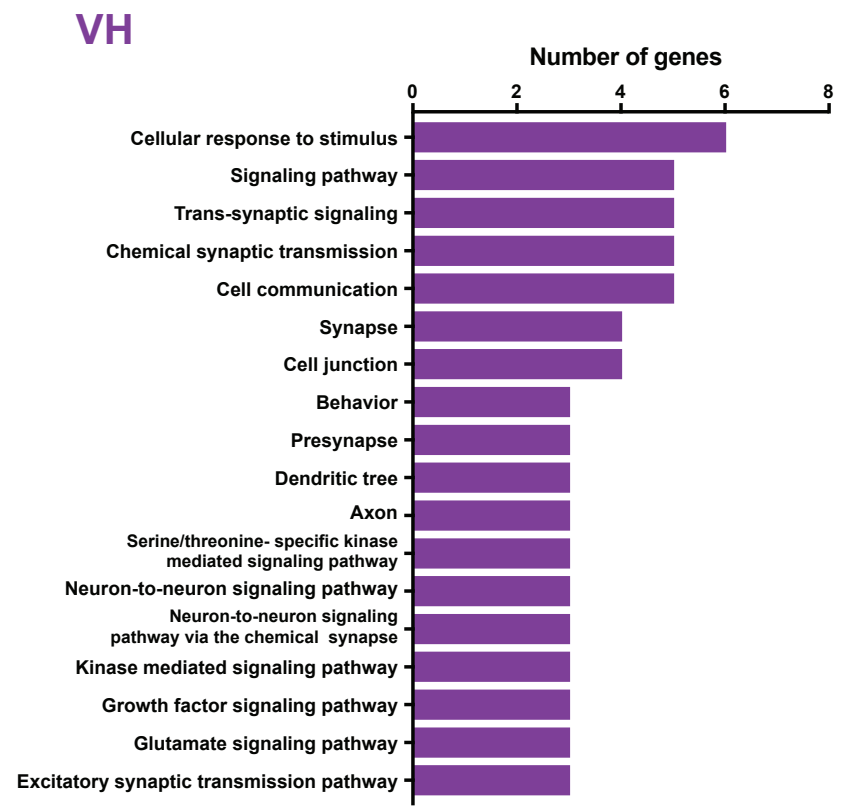

B

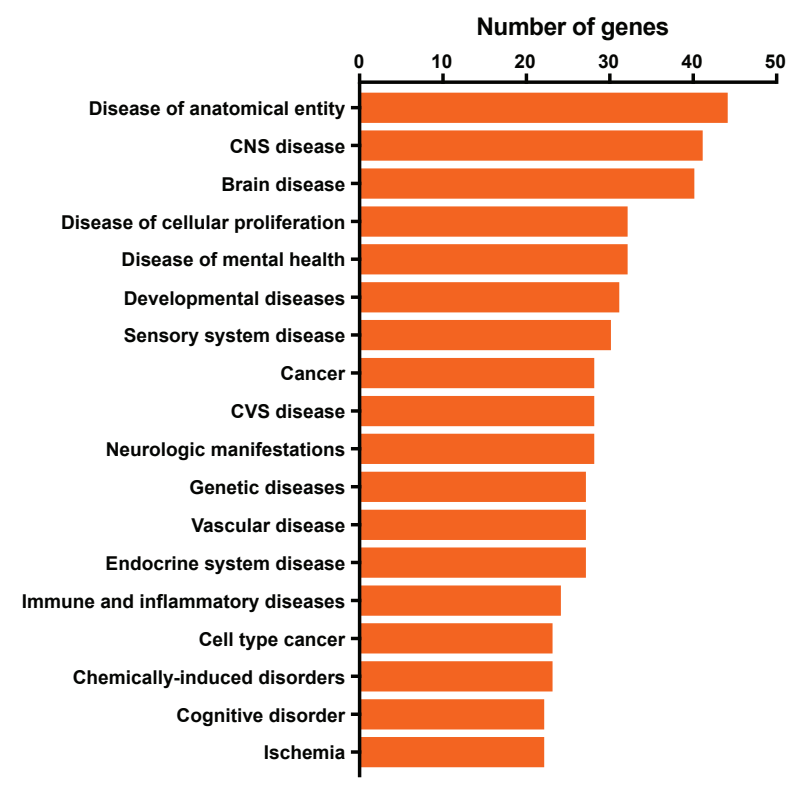

D

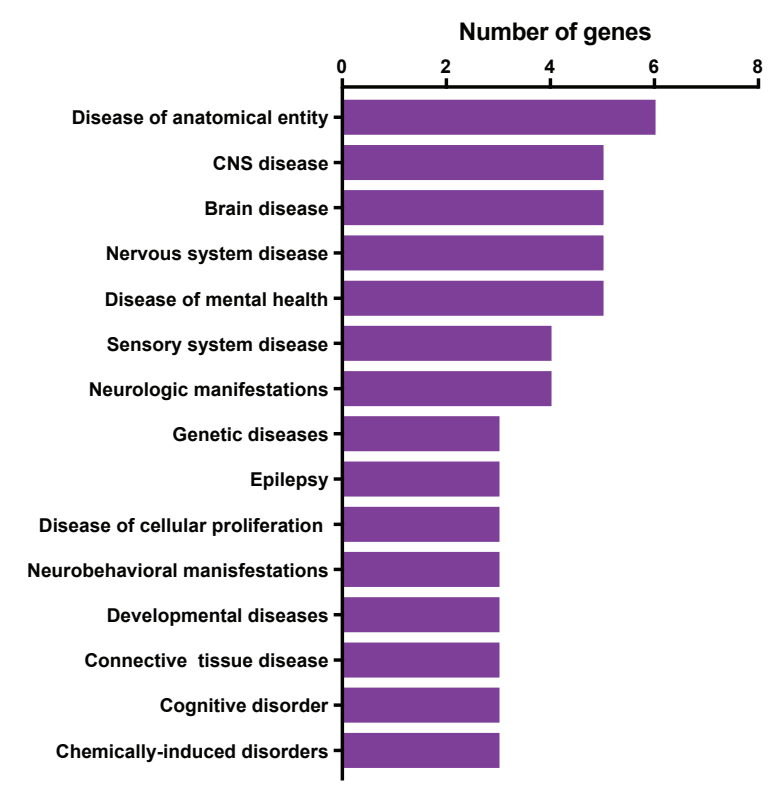

